\title{
Assessment of the Driving Factors Affecting Electricity Consumption in Africa Using Index Decomposition Analysis and Satellite Derived Data
}

\author{
Almaz Akhmetov ${ }^{1, *}$ and Augusto Vundo ${ }^{2}$ \\ 1 Orizon Consulting, McLean VA, USA \\ 2 University of Tsukuba, Graduate School of Life and Environmental Sciences, Tsukuba, Japan \\ *E-mail: akhmalm@orizonllc.com
}

\begin{abstract}
Inadequate electricity access limits human development and affects quality of life in Africa. Hence, the improvement of electricity access has become a cornerstone of the African energy policy. This study proposes the use of satellite derived data of nighttime lighting, population count and Index Decomposition Analysis (IDA) to identify the driving factors for changing in electricity consumption in Africa between 2000 and 2013. The results of decomposition analysis indicated that population growth throughout the continent resulted in increased electricity consumption, while other factors had different effects. The results of this study could contribute to the design of better energy policy to achieve sustainable development of the continent.
\end{abstract}

Keywords: Africa, decomposition analysis, nighttime lighting, population count, electricity consumption.

ENGINEERING JOURNAL Volume 22 Issue 1

Received 18 June 2017

Accepted 18 November 2017

Published 31 January 2018

Online at http://www.engj.org/

DOI:10.4186/ej.2018.22.1.27 


\section{Introduction}

Universal access to modern energy is crucial to achieve sustainable development in Africa [1]. Central deficiency of African energy system, primarily in Sub-Saharan Africa, is the limited access to electricity. For example, average annual per capita residential electricity consumption of the household with electricity access in Sub-Saharan Africa (excluding South Africa) is around half the average amount of China, 20\% of Europe and about $7 \%$ of the USA [2]. In general, energy poverty undermines education, healthcare and economic development of the vast majority of African nations. Hence, addressing this issue has become a regional energy policy challenge.

Energy development in the continent needs to keep pace with economic aspirations of the continent [2]. Kebede et al. (2010) identified the presence of positive relationship between economic growth and energy use and 1\% GDP increase requires $0.55 \%$ increase in energy use in Sub-Saharan Africa [3]. Massive internal and external investments are required to improve energy access in Sub-Saharan Africa [4-5]. Moreover, there is no universal policy to ensure expansion of energy sectors due to significant regional diversity in energy systems, energy consumption economic structures and population structures [4-7].

It is proven that improved access to electricity has positive impact on African nations ' health and education systems and private sector`s productivity [8]. However, power sectors of African states are significantly underdeveloped comparing to other developing countries [9]. Another constraint to development of the continent is the low reliability of electricity supply. It is estimated that the alleviation of electricity poverty in Sub-Saharan Africa requires almost 40 times increase of the electrification rate [10].

There are multiple international initiatives aiming to eradicate energy poverty in Africa. The African Development Bank focuses on technologies and subsectors that are important to address current and future energy demand of the content, including renewable energy, project related to fossil fuels, power transmission and distribution, region cooperation and supply- and demand-side energy efficiency measures [11]. To address the regional energy crisis, the Economic Community of West African States (ECOWAS) plans to attract private investments in energy efficiency and increase the use of renewable energy to address energy security and access challenges in the region [12-13]. The USAID-led "Power Africa" initiative aims to install additional $30 \mathrm{GW}$ of power generation capacity, primarily renewable energy, to provide access to 60 million homes and businesses across the continent [14]. Akon Lighting Africa project intents to develop solar power solutions to provide electricity access to African villages [15]. As a part of its global "Shaping the Future of Energy" initiative, the World Economic Forum facilitates activities aiming to understand opportunities and obstacles to achieve universal electricity access in Africa through public private collaboration [16]. The Africa renewable energy initiative under African Heads of State and Government on Climate Change is set to utilize the renewable energy potential of the continent [17].

The continent possesses significant, but so far untapped energy resources [18-19]. In particular, utilization of abundant renewable energy resources considered being a solution to the existing energy crisis [1]. However, effective exploitation of the potential as well as development of adequate energy policy requires thorough understanding of driving factors behind electricity consumption in Africa.

\section{Literature Review}

Index Decomposition Analysis (IDA) has been widely utilized to assess changes in aggregate national and regional energy consumption. Furthermore, several studies used decomposition analysis of sectoral energy consumption in Africa.

Karekezi (2002) indicated that changing population structure and economic growth are the main factors behind the growing demand for modern energy services [7]. It was defined that the urbanization and growing wealth are the key drivers of demand. The study demonstrated inadequate energy services for the poor in Africa.

Ben Hammamia et al. (2014) utilized the Fisher Ideal Index decomposition methodology to decompose energy intensity in Tunisia into two factors: structural change of the economy and energy efficiency [20]. It was identifies that improved energy efficiency was the main driving factor in reduction of energy intensity in the period 1990-2008. Additionally, increased role of service sector in the Tunisian economy also contributed to reduction of the energy intensity.

Iglesi-Lotz and Blignaut (2011) utilized the three factor (output, structural changes and efficiency improvements) sectoral decomposition analysis to define the driving forces of electricity consumption in the 
South African economy for the period 1993-2006 [21]. The results indicated that the sectoral activities were the primary factor behind the increase in electricity consumption, followed by structural changes. Efficiency improvements were not sufficient to offset the combined effects of output and structural effects on electricity consumption.

Olanrewaju et al. (2013) developed a combined Index Decomposition Analysis-Artificial Neural Network-Data Envelopment Analysis (IDA-ANN-DEA) model to assess the industrial energy consumption in South Africa for the period 1971-2008 [22]. Energy consumptions of the 11 sectors were decomposed into three explanatory factors: activity, structure and energy intensity. The results of IDA indicated that the activity had the biggest effect on energy consumption, while the structure and intensity effects were negligible.

Decomposition analysis of residential electricity consumption in the United States of America indicated that the number, the size of the homes and increased electricity intensity per foot caused significant rise in electricity use [23]. Decomposition analysis of regional energy and electricity consumption and consequent ranking of the regions in China and India respectively revealed different driving factors and significant regional differences in consumption and saving potential, implying the need for distinctive regional energy saving policy needs [24-25]. Decomposition analysis of household electricity consumption in Indonesia indicated significant contribution of electrified households to GDP, while the effects of intensity and efficiency were smaller [26].

The night-time light (NTL) satellite data was used in research for different purposes, from urban land extraction and poverty analysis [27, 28-31]. Furthermore, the NTL data was widely used to assess economic and energy poverty in Africa. For example, Elvidge et al. (2009a) produced a global poverty map using satellite data of population count and NTL [27]. A poverty index was calculated by dividing population count by NTL. Authors assumed that areas with higher population counts and lower NTL in developing countries would have higher poverty level and vice versa. NTL was considered as a proxy for wealth. It was estimated that there were 20 African countries among the countries with population larger than 10 million and poverty level higher than $50 \%$. African countries with greater than $80 \%$ poverty level were Ethiopia, Burkina-Faso, Madagascar, Uganda, Tanzania, Malawi and Niger, while the country with the lowest poverty rate (34\%) was South Africa.

Doll and Pachauri (2010) utilized global datasets of NTL, a gridded population dataset and a global urban area dataset to estimate population without access to electricity by comparing satellite data to the International Energy Agency (IEA) statistics on electricity access between 1990 and 2000 [32]. The study showed the decline of population without access to electricity in North Africa, while in Sub-Saharan Africa population without electricity increased, indicating the slow progress in providing electricity assess in the latter region. It was partially due to the low population densities in rural areas.

Min et al. (2013) used NTL imagery to detect rural electrification of the villages in Senegal and Mali by comparing satellite data with survey data [33]. The study utilized a direction algorithm based on NTL and the geographic location of the villages to classify electrified villages. It demonstrated the direct correlation between NTL and access to electricity of the villages. Electrified villages appeared to be brighter and viceversa.

This paper aims to identify factors of electricity consumption in Africa using three-factor (electricity intensity of the economies, economic activity and population) decomposition analysis and assessment of NTL satellite data for the period 2000-2013. On top of that, the study investigates the changes in energy profiles, electricity production and consumption patterns of African states during the same period. It also reviews demographics and socioeconomics of the countries. The ultimate goal of this study is to contribute to the existing research and better understanding of the African energy system.

The rest of this paper is organized as follows. A brief overview of energy profiles of African countries with focus on electricity sector is done in Chapter 3. Chapter 4 describes methodology and sources of data. The results are presented and discussed in Chapter 5. Chapter 6 provides conclusions of this research and future studies.

\section{Energy Profiles of African Countries}

Africa possesses more than sufficient energy resources to satisfy its demand [2]. However, the potential remains mainly untapped. Underdeveloped electricity infrastructure and population trends are the main obstacles to African energy and economic development [2,6]. Furthermore, energy profile and the relationship between energy consumption and economic growth in the African countries are notably divergent [34]. 
Electricity consumption in Sub-Saharan Africa is the lowest in the world [35], while Northern African countries consume significantly more electricity. There are significant disparities in electricity consumption among the African countries as displayed in Fig. 1. South Africa is the highest consumer of electricity on the continent. In contrast, Guinea-Bissau consumed only $35 \mathrm{GWh}$ of electricity in 2013, which constituted only $0.02 \%$ of South Africa`s total final electricity consumption. Top-10 countries consume $84 \%$ of total final electricity in Africa. Share of electricity in the total final consumption (TFC) is generally higher in more developed countries and Small Island Developing States (SIDS). Lower share of electricity consumption in the TFC are primarily observed in countries with significant energy resources and the less developed countries.

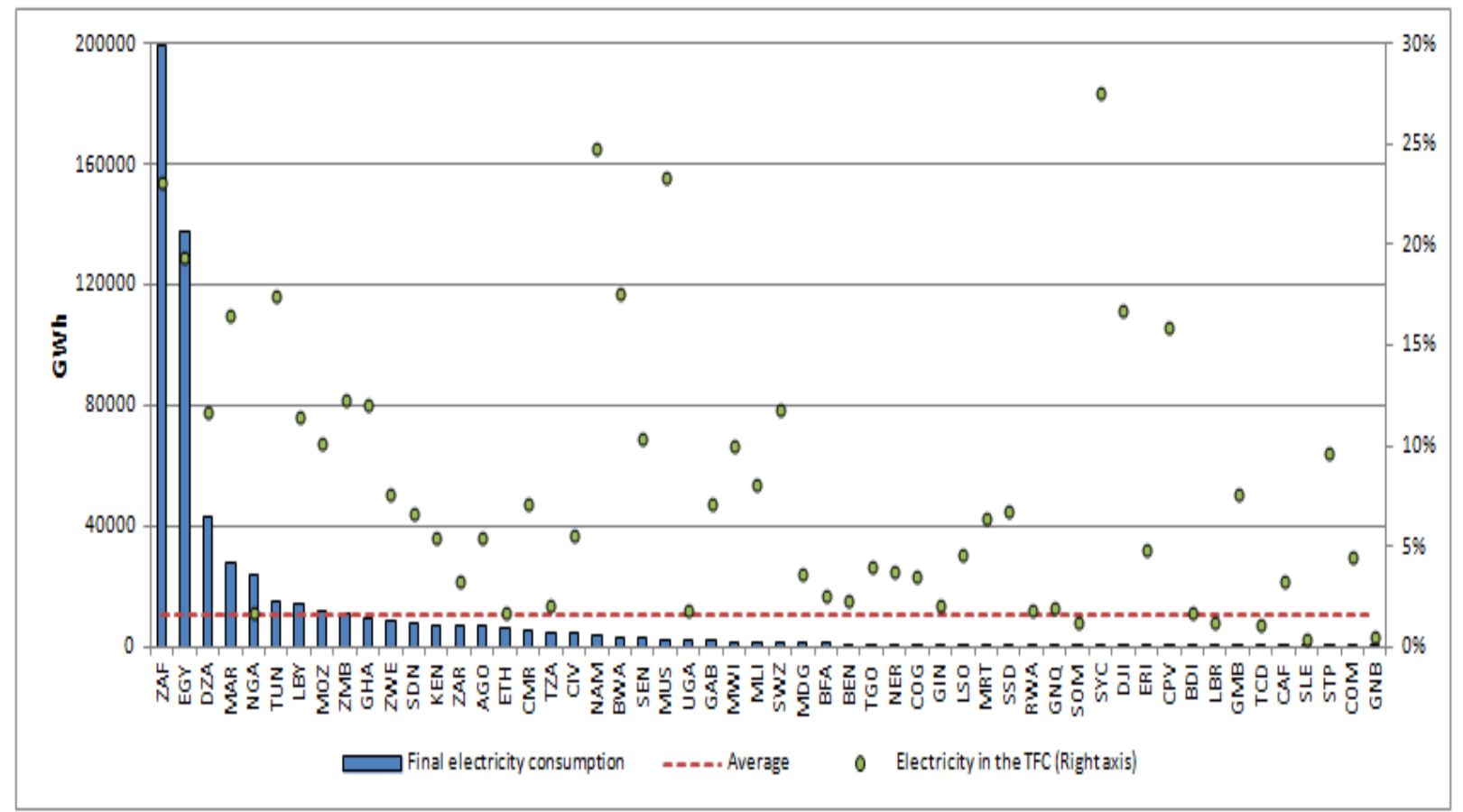

Source: Authors`calculations using UN data [36].

Fig. 1. Final electricity consumption in Africa in 2013.

There are also substantial variations in installed capacities due to alterations in socio-economic factors, infrastructure development and resources availability. African countries with the largest installed capacities are South Africa and Egypt. Island nations of Comoros and Sao Tome and Principe are notable for their low installed capacities on the continent. Total installed capacities have declined in Eritrea, Seychelles and Zimbabwe by 25 MW, 3 MW and 2 MW respectively since 2000. Meanwhile, total installed capacity in Equatorial Guinea has increased by almost $3000 \%$ since 2000 due to utilization of abundant hydrocarbon resources and hydropower potential.

Electricity fuel mix in Africa varies significantly from one country to another due to availability of energy sources. South Africa is the largest electricity consumer of the continent and only country with operating commercial nuclear reactors. Oil products $(52 \%)$ dominate the fuel mix for electricity production in Africa, followed by hydropower $(20 \%)$ and natural gas $(16 \%)$ as seen in Fig. 2. Coal is the dominant fuel in South Africa, Botswana, Niger, Morocco, Mauritius and Zimbabwe. Non-hydro renewable energy constitutes only $0.1 \%$ of the TFC of the continent. The largest producers of non-hydro renewable energy are Kenya (4\%), Cabo Verde (1\%) and Ethiopia (1\%). The African Great lakes and the river Nile are important for hydropower production for the countries located around the reservoirs. 


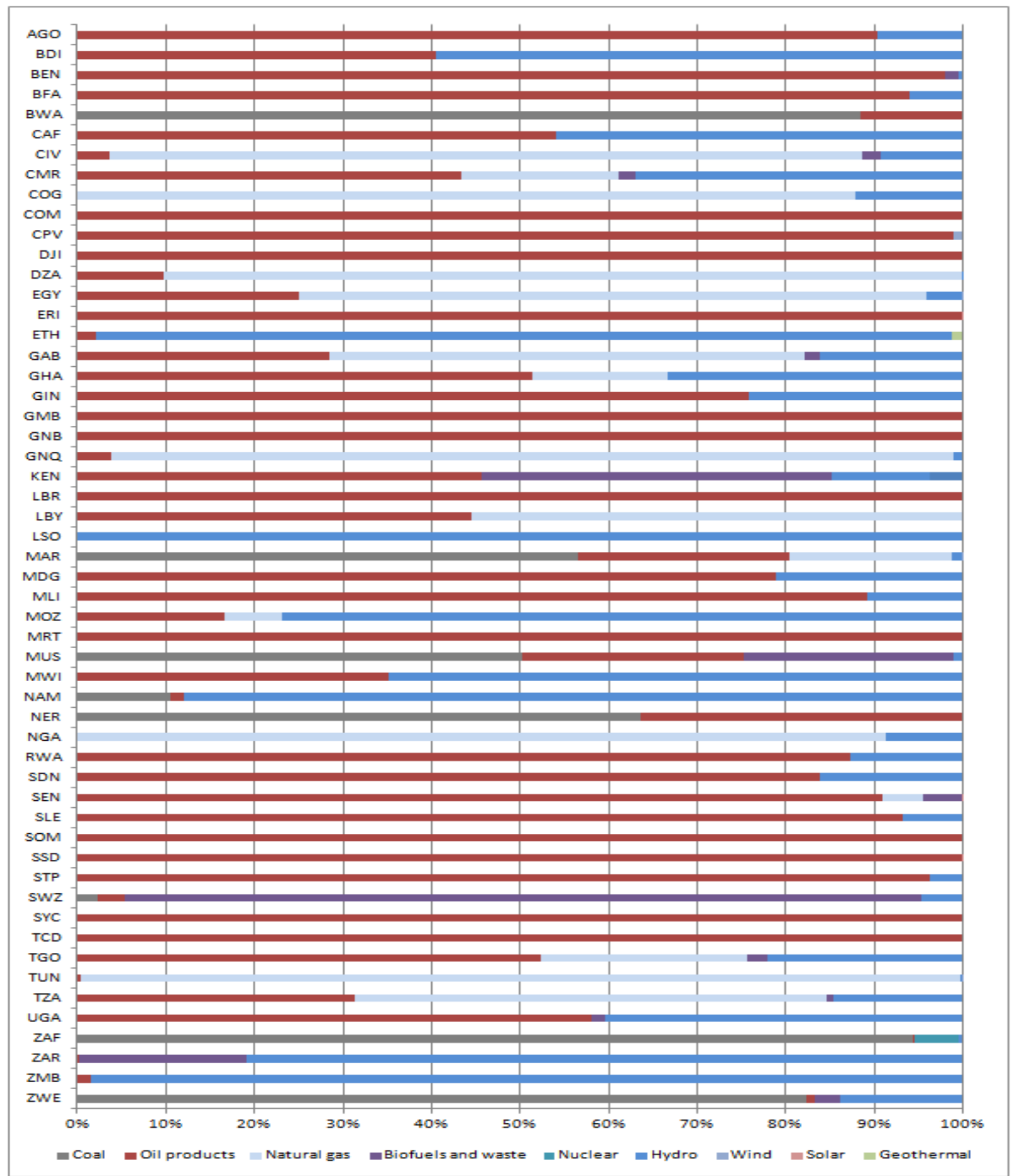

Source: Authors`calculations using UN data [36].

Fig. 2. Fuel shares of total electricity generation in Africa in 2013.

Industry $(43 \%)$ is the largest consumer of electricity, followed by residential $(33 \%)$ and other sectors $(24 \%)$ in the continent as seen in Fig. 3. In Mozambique industry accounts for $80 \%$ of final electricity consumption, while the residential consumption (83\%) is the largest in Gambia. Electricity is used by households primarily for lighting and electrical appliances, while it is widely unaffordable for cooking in Africa [37]. It is likely that the share of residential sector in many African countries would be higher if better access to electricity was achieved. 


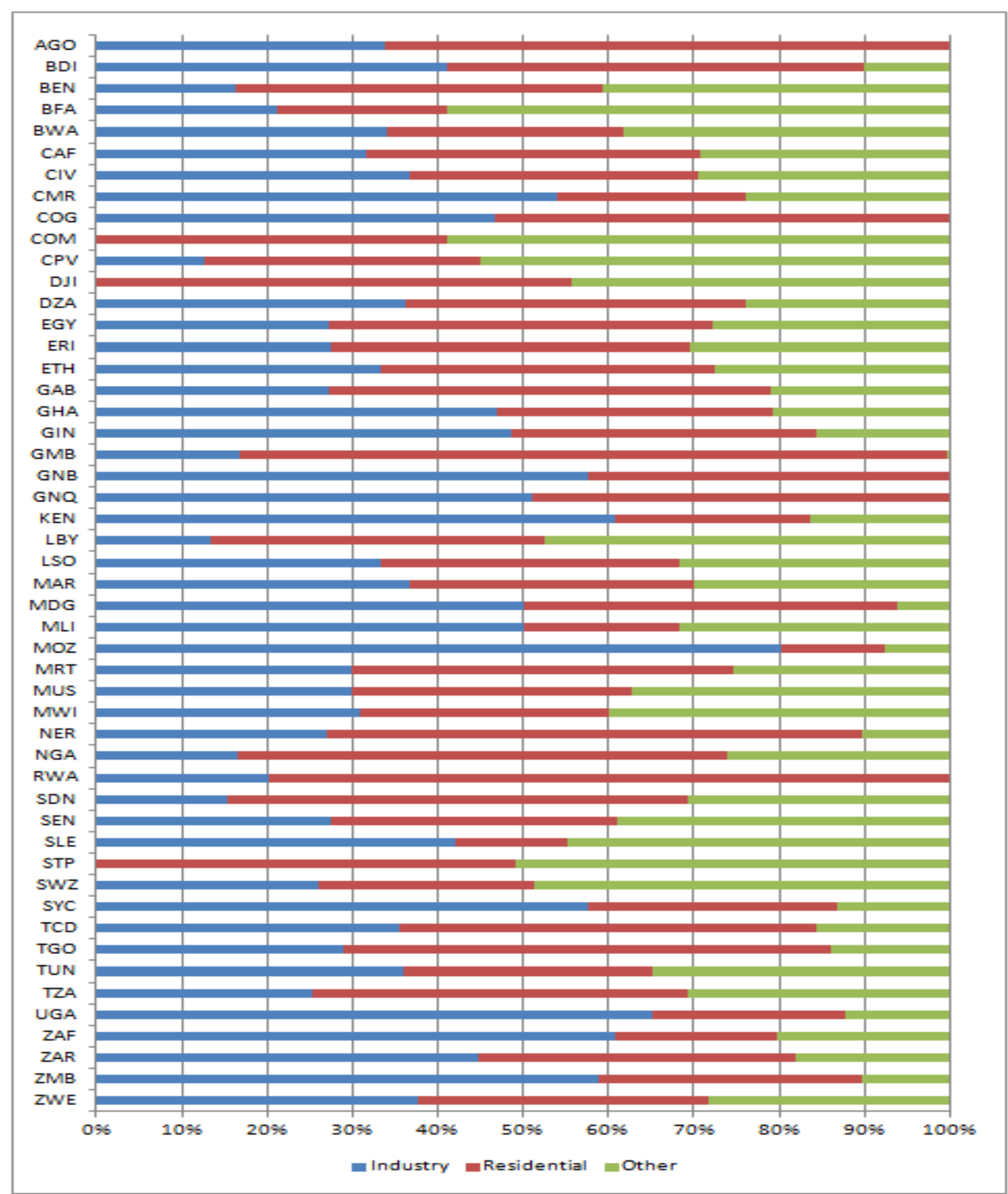

Source: Authors' calculations using UN data [36].

Fig. 3. Final consumption of electricity by sector in Africa in 2013 .

According to the World Bank data [38], 828 million people in Africa do not have access to electricity, of which 495 million live in rural area and 333 million live in urban area. All population of Northern African countries has access to electricity, while only about $5 \%$ of South Sudanese have access to electricity as presented in Fig. 4. Continent-wide about $70 \%$ of urban population and $27 \%$ of rural population have access to electricity. Poverty, gross domestic savings, corruption, share of rural population and population density are the main factors of the electricity access variations in Sub-Saharan Africa [6]. 


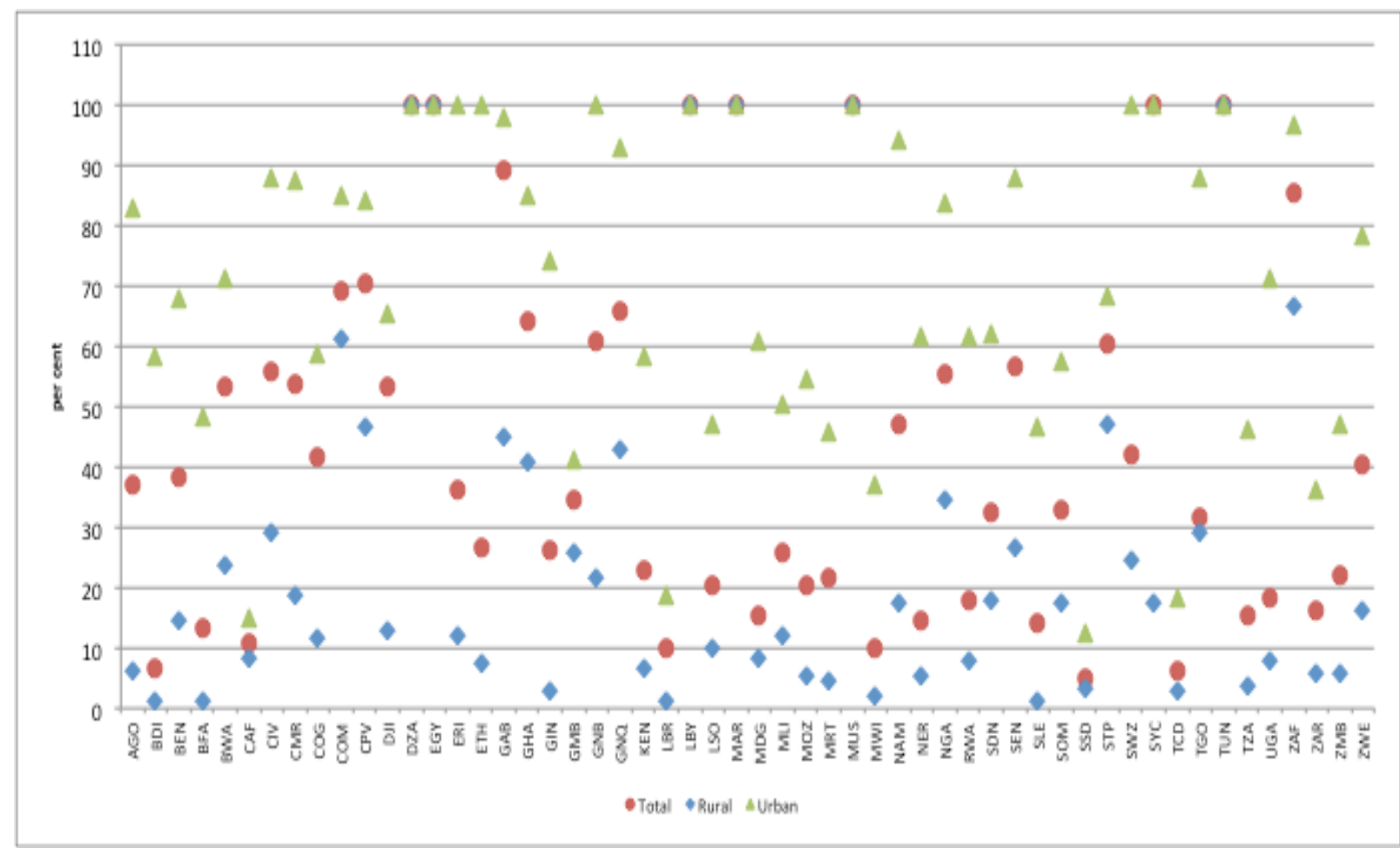

Source: Authors' calculations using World Bank data [38].

Fig. 4. Access to electricity of urban and rural population in Africa in 2012.

Significant variations in electricity profiles of African countries imply the need for the country specific energy policies based on analysis factors of electricity consumption in Africa. Understanding the main reasons for underlying changes in electricity consumption can assist in addressing energy security of the African countries. To the best authors ' knowledge, this is the first continent wide attempt to perform decomposition analysis electricity consumption and satellite derived data assessment.

\section{Data and Methodology}

This study utilizes temporal decomposition analysis of economic and demographic factors affecting electricity consumption and spatial assessment of satellite derived NTL and population count. After that, the results of decomposition analysis are combined with satellite data. Socio-economic and electricity indicators of the countries under analysis are presented in Appendix I.

\subsection{Decomposition Analysis of Electricity Consumption}

Index Decomposition Analysis is the preferred methodology in energy studies to investigate factors influencing energy consumption [39]. The Logarithmic Mean Divisia Index (LMDI) is the preferred method among the existing IDA methodologies due to theoretical robustness, adaptability, and availability of perfect decomposition [40]. This study aims to conduct decomposition analysis of the factors affecting total electricity consumption between 2000 and 2013 in the African countries. Total electricity consumption is decomposed into three explanatory factors as follows:

$$
\sum_{i} E_{i}=\sum_{i} P_{i} \frac{E_{i}}{Q_{i}} \frac{Q_{i}}{P_{i}}=\sum_{i} P_{i} I_{i} A_{i}
$$

where $E_{i}$ is the total final electricity consumption $(\mathrm{GWh})$ in country $i . Q_{i}$ is the Gross Domestic Product (GDP) (Purchasing Power Parity [PPP] based constant 2011 international USD) in country $i, I_{i}$ is the electricity intensity of GDP (GWh/PPP constant 2011 international USD) in country $i, A_{i}$ denotes economic activity (PPP constant 2011 international USD per capita) in country $i$, and $P_{i}$ is the total population in country $i$. 
Total changes in electricity use between target year (2013) and base year (2000) is expressed as follows:

$$
\Delta E_{i}=E_{i}^{2013}-E_{i}^{2000}=\Delta E_{\text {pop }}+\Delta E_{\text {int }}+\Delta E_{\text {act }}
$$

where $\Delta E_{\text {pop }}$ is the changes in electricity consumption caused by changes in population, $\Delta E_{\text {int }}$ denotes changes in electricity consumption due to changes in electricity intensity of GDP, and $\Delta E_{\text {act }}$ is the changes in electricity use caused by changes in economic activity.

The explanatory factors are expressed as follows:

$$
\begin{gathered}
\Delta E_{\text {pop }}=\sum_{i} w_{i} \ln \left(\frac{P_{i}^{2013}}{P_{i}^{2000}}\right) \\
\Delta E_{\text {int }}=\sum_{i} w_{i} \ln \left(\frac{I_{i}^{2013}}{I_{i}^{2000}}\right) \\
\Delta E_{\text {act }}=\sum_{i} w_{i} \ln \left(\frac{A_{i}^{2013}}{A_{i}^{2000}}\right)
\end{gathered}
$$

Due to limited data availability, Eritrea, Somalia, and Western Sahara are excluded from data decomposition analysis, but available for NTL and population count assessment. For the purpose of analysis, data for former Sudan (including South Sudan) is used for decomposition analysis. Total number of countries analyzed is 51 . Total electricity consumption data is from UN Data [36], while GDP data in Purchasing Power parity based 2011 international USD and population data are acquired from World Bank data [38]. Table 1 presents the overview of the indicators considered in this study.

Table 1. Electricity consumption indicators.

\begin{tabular}{lccccccc}
\hline Indicator & Unit & \multicolumn{2}{c}{ Mean } & \multicolumn{2}{c}{ Max } & \multicolumn{2}{c}{ Min } \\
& & $\mathbf{2 0 0 0}$ & $\mathbf{2 0 1 3}$ & $\mathbf{2 0 0 0}$ & $\mathbf{2 0 1 3}$ & $\mathbf{2 0 0 0}$ & $\mathbf{2 0 1 3}$ \\
\hline$E$ & TWh & 6.72 & 11.43 & 162.52 & 199.31 & 0.02 & 0.04 \\
$P$ & Mln. & 15.7 & 21.8 & 122.9 & 172.8 & 0.1 & 0.1 \\
$A$ & PPP (2011) USD/capita & 4111 & 5665 & 21997 & 34233 & 518 & 561 \\
$I$ & MWh/Mln. PPP (2011) USD & 51 & 51 & 372 & 424 & 7 & 6 \\
\hline
\end{tabular}

Although there is internationally accepted definition of official electricity consumption, in international practice statistics is usually referred as official statistics if it follows the United Nations Fundamental Principals of Official Statistics [41]. The UN electricity consumption data are collected from the national official statistical agencies following methodological recommendations from the United Nations on the sources, methods and procedures of the statistics [42]. Furthermore, the United Nations have also developed specific recommendations for countries with less sophisticated data compilation and analysis technique [43].

Three most common methods to convert GDP into a common currency are nominal, real and purchasing power parity. Nominal GDP uses market exchange rate and does not take into account differences in the cost of living in different countries. The indicator could be used for spatial analysis in a given year. Real GDP adjusts the value of economic output for price changes between different time periods. The indicator could be suitable for temporal decomposition analysis. However, a combination of temporal decomposition analysis and spatial analysis of NTL and population count requires a macroeconomic measure of the value of GDP adjusted to the cost of living in different countries of the continent. Hence, GDP PPP is more useful when comparing difference in living standards between the African nations.

Mean values of all indicators, apart from electricity intensity, have increased since 2000. Electricity consumption in more developed countries has grown larger than in the least developed countries in Africa. Faster population growth (more than 50\%) was observed in DR Congo, Gambia, Mali, Niger and Uganda. Faster economic growth (more than 100\%) was observed in Chad, Equatorial Guinea, Ethiopia, and Mali, while GDP per capita has declined in Central African Republic, Comoros, Cote d'Ivoire, Liberia, Libya, Madagascar, and Zimbabwe since 2000. Average continent-wide electricity intensity of GDP has not changed since 2000. Electricity intensity has grown faster (more than 100\%) in Angola, Gambia, and Mozambique, 
while the indicator has declined in Chad, DR Congo, Ghana, Guinea, Malawi, Mali, Namibia, Sierra Leone, South Africa, Swaziland, Uganda, Zambia, and Zimbabwe.

\subsection{Assessment of NTL and Population Count}

The NTL dataset is a very import source of information for electricity consumption analysis. This data can be easily accessed, thus giving an opportunity for researchers to explore and understand the elements involved in the energy sectors. This study focused on Africa as a whole with some special cases highlighted as they stood out during the analysis.

Satellite derived data of NTL and the gridded human population of the world on a continuous raster surface were used for analysis. Since the release of the first version in 1995, the essential inputs to Gridded Population of the World (GPW) have been population census and administrative boundaries. The purpose of GPW v4 is to provide a spatially-disaggregated population layer that is compatible with datasets from social, economic, Earth science disciplines, and remote sensing data. It provides globally consistent and spatially explicit data for use in research, policy-making, and communications [44]. These datasets are constructed from national or sub-national input for administrative units. GPW v4 is gridded with an output resolution of 30 arc-seconds, or $\sim 1 \mathrm{~km}$ at the equator. Separate grids are available for $\mathrm{UN}$-adjusted population counts, population density, data quality indicators, and land and water areas [44]. In total, eight datasets within the GPW v4 are available. Three datasets from this collection were used, namely the UN-Adjusted Population Count v4, Land and Warer Area v4, and National Identifier Grid v4. The land and water area were used as a mask for the UN-Adjusted Population Count, v4 for years 2000, 2010 and 2015. Unfortunately in the GPWv4 data there is no information for year 2013, consequently the average of the years 2010 and 2015 was used for year 2013. Then the continent was split into countries using National Identifier Grid, v4. To avoid any mismatch in terms of area or country extension between the datasets, the GPW v4 and the NTL used the same National Identifier Grid v4.

The NTL data was acquired from the National Oceanic and Atmospheric Administration`s National Geophysical Data Center [45]. The Global Gas Flares data was also used as a mask for the African countries with oil and gas activities [46]. According to Elvidge et al. (2009b), in the production of the gas flares polygon vectors each of the Defense Meteorological Satellite Program (DMSP) features suspected to be gas flares and inspected in higher resolution remote sensing data available in Google Earth [47].

Both the NTL and the population data are version 4 and have an output resolution of 30 arc-seconds or $\sim 1 \mathrm{~km}$, and were reprojected to Geographic Lat/Lon WGS_1984 geographic coordinate system. The NTL are cloud-free composites of the highest quality. In cases where two satellites collected data, the composites were produced [45]. The NTL data F142000, F152000 and F182013 were used for this analysis. For the data where two composites were present, the case of year 2000, an average was taken in order to avoid any missing information that could be present in one satellite and missing in the other. If only one satellite data was available, no changes were made. Each country data was subset by using the national identifier grid shapefile from the Socioeconomic Data and Applications Center (SEDAC) for both the NTL and population count [48].

After extracted by country, the NTL data was further refined through the gas flares shapefile in countries with gas flares to remove them from the NTL data composite. A total of 17 countries were masked for gas flares. If there was any problem related to the shapefiles, the $\mathrm{kmz}$ files were used to support the identification and demarcation of the respective gas flares on the ground by using the high-resolution Google Earth imagery. For example, in Nigeria the mask area includes a big number of cities such as Koko, Orhuwhorun, Islokolo, Yenagoa and Port-Harcourt, just to mention a few. Therefore, the shapefiles for flare gas were adjusted guided by the original from the DMSP product. Once refined the raster data was extracted given the condition NTL $>0$. Only pixels with a digital number (DN) greater than 0 were used, knowing that the DN ranges from 0 to 63, and this process was done using ArcMap 10.1 and ENVI version 5.1. The same condition was given to the UN-Adjusted Population Count. From the extracted pixels mean values were calculated for each country on the yearly basis and further used in the analysis

Many researchers have pointed out some drawbacks of the NTL data, e.g. the so-called "overglow", which tends to over-represent the extent of lit area [49]. In most of the studies a threshold is set depending on the purpose of the research. Many areas in Africa have no NTL, but have population present causing a gap between the existing population and the non-lit area. It is assumed that the overglow phenomenon can actually have a positive effect. In a sense, that it is an indicator of the increase in the actual NTL. 


\section{Results and Discussion}

The results of the study are organized into the sections, reporting the results of decomposition analysis, NTL and population count assessment and combined results of decomposition and satellite derived data analyses. The states are grouped into three groups based on mean NTL: high (NTL>1000 km²); medium (1000 $\left.\mathrm{km}^{2}>\mathrm{NTL}>100 \mathrm{~km}^{2}\right)$ and low $\left(\mathrm{NTL}<100 \mathrm{~km}^{2}\right)$.

\subsection{Results of Decomposition Analysis}

The results of decomposition analysis are presented in Appendix II. Total electricity consumption in all 51 countries has increased by almost $70 \%$ since 2000 . However, the growth was unequal. High NTL countries has accounted for $74 \%$ of total increase in electricity consumption, followed by medium NTL countries $(22 \%)$ and low medium NTL countries $(4 \%)$. The biggest electricity consumption increase occurred in Mozambique (by 1046\%), while consumption in Zimbabwe and Sierra Leone declined by 21\% and 15\% respectively.

Average electricity consumption by high NTL countries has increased by $104 \%$ since 2000 . The biggest increase occurred in Nigeria and the lowest was in South Africa. Electricity intensity of GDP was the main relative factor that has affected electricity consumption in Algeria, Libya and Tunisia, while changes in economic activity have had the biggest effect in Egypt, Morocco, Nigeria and South Africa. $\Delta E_{\text {int }}$ was the highest in Algeria and the factor caused the relative decline in South Africa by $21 \%$. It is possible that the decline in the latter might indicate improvements in energy efficiency. $\Delta E_{a c t}$ was the highest in Nigeria and the factor caused the relative decline in Libya by $14 \%$. The decline in the latter was likely caused by Libyan civil war. $\Delta E_{\text {pop }}$ was the positive relative factor on electricity consumption in all high NTL countries with the highest effect in Nigeria and the lowest in Libya.

Average electricity consumption by medium NTL countries has increased by $205 \%$ since 2000 . The biggest increase was observed in Mozambique and the electricity consumption declined in Zimbabwe. Electricity intensity of GDP was the main relative factor in Angola, Congo, Mozambique and Sudan (former). Economic activity was the main relative factor in Botswana, Ethiopia, Ghana, Namibia, Tanzania and Zambia. Population was the main relative factor in Cameroon, Cote d'Ivoire, DR Congo, Kenya, Senegal and Zimbabwe. $\Delta E_{\text {int }}$ was the highest in Mozambique and caused the biggest relative decline in Ghana. It is possible that the energy efficiency contributed to relative decline in electricity consumption in Ghana and Namibia due to high access to electricity, while in DR Congo, Zambia and Zimbabwe the relative decline was caused by insufficient electricity supply. $\Delta E_{a c t}$ was the highest in Mozambique and caused the biggest relative decline in Zimbabwe. The latter is likely was caused by considerable economic hardship. $\Delta E_{\text {pop }}$ was the positive relative factor on electricity consumption in all medium NTL countries with the highest effect in Mozambique and the lowest in Zimbabwe.

Average electricity consumption by low NTL countries has increased by $124 \%$ since 2000 . The biggest increase occurred in Equatorial Guinea and the consumption of electricity declined in Sierra Leone. Electricity intensity of GDP was the main relative factor in Central African Republic, Comoros, Gabon, Gambia and Sao Tome and Principe. Economic activity was the main relative factor in Cabo Verde, Chad, Djibouti, Equatorial Guinea, Lesotho, Mali, Mauritius, Rwanda, Seychelles, Sierra Leone and Uganda. Population was the main relative factor in Benin, Burkina Faso, Burundi, Guinea, Guinea-Bissau, Liberia, Madagascar, Malawi, Mauritania, Niger, Swaziland and Togo. $\Delta E_{\text {int }}$ was the highest in Equatorial Guinea and caused the biggest relative decline in Sierra Leone. It could be argued that the relative decline caused by the indicator in low NTL states was due to insufficient electricity supply. $\Delta E_{a c t}$ was the highest in Equatorial Guinea and caused the biggest relative decline in Central African Republic. $\Delta E_{\text {pop }}$ was a positive relative factor on electricity consumption in all low NTL countries with the highest effect in Equatorial Guinea and the lowest in Mauritius.

Uncertainties of energy decomposition analysis results are associated with quality and selection of data source [24]. For example, using real GDP instead of the output adjusted to PPP may lead to different decomposition results [50]. Furthermore, using electricity consumption from other sources (i.e., International Energy Agency or national statistical agencies) might also lead to different outcomes. 


\subsection{Results of NTL and Population Count Assessment}

The NTL data from 2000 and 2013 for African countries has shown a mixture in terms of increase and decrease in lit area as seen in Fig. 5. Our analysis showed that all African countries had an increase in NTL, however some countries with a high and others with a minimum increase. Countries like Congo, Equatorial Guinea, Kenya, Liberia, Zimbabwe and Gambia presented a minimum $\left(1 \mathrm{~km}^{2}\right)$ increase of NTL among the African countries. On the other hand, Tunisia, Ghana, Tanzania, Egypt, Angola, Cape Verde and Mozambique have shown the highest increase in NTL from 2000 to 2013 and it varies from $381 \mathrm{~km}^{2}$ in Angola and $4089 \mathrm{~km}^{2}$ in Tunisia.

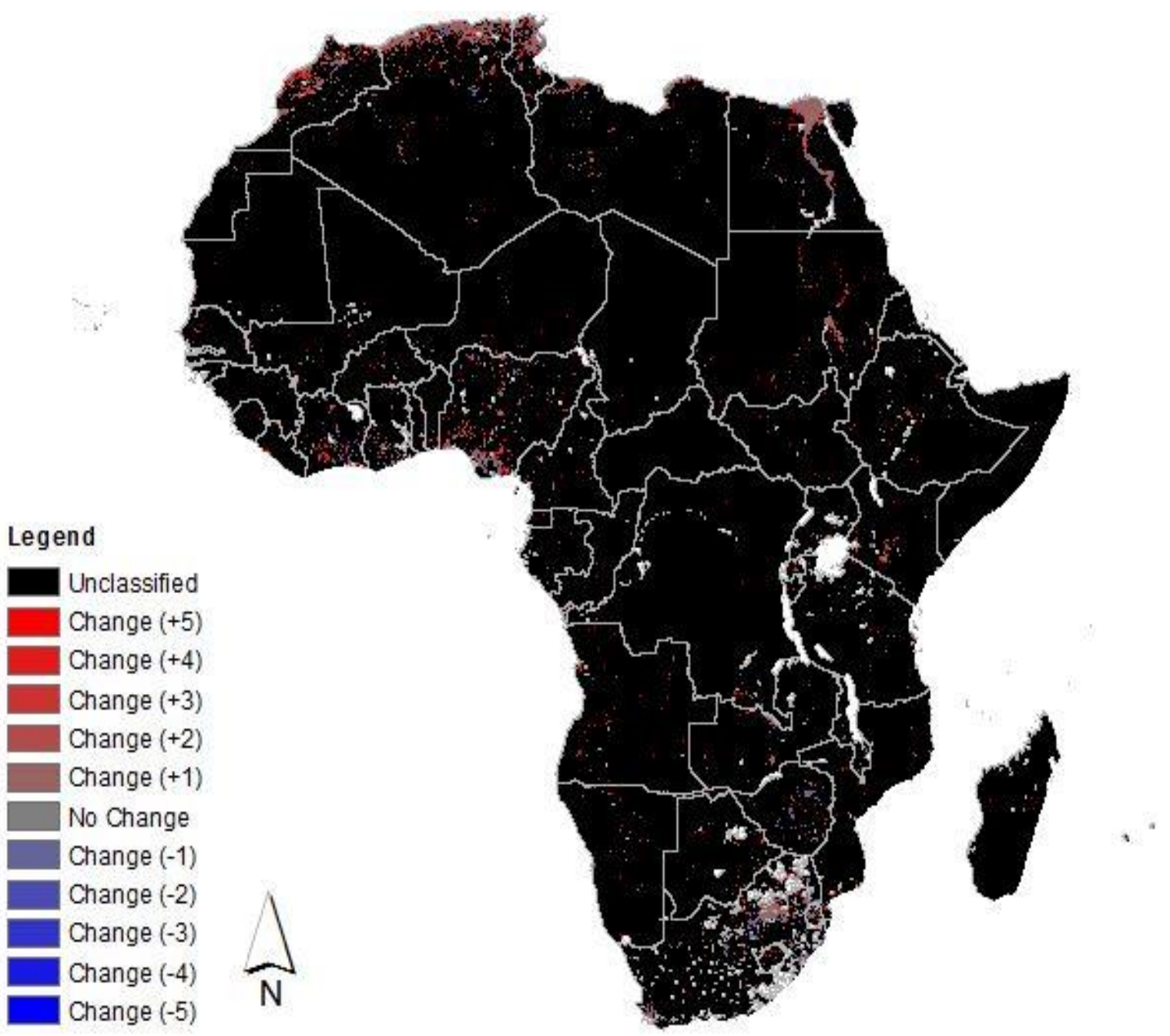

Fig. 5. Changes in NTL $\left(\mathrm{km}^{2}\right)$ between 2000 and 2013.

From these results, it is obvious the presence of countries with high growth in electricity intensity more than $100 \%$, Angola, Gambia, and Mozambique, at the same time countries with more than $50 \%$ in population growth. Although some countries have increased their NTL, it may not be related to their total electricity consumption, especially in Africa where few infrastructures are capable of functioning in the evening. Mozambique has shown the biggest increase in electricity consumption and it has also increased NTL, but from its total consumption only $20 \%$ goes to the residential. This increase can be justified by the increase in population and GDP. Two countries from the northern part of Africa have also shown an increase in NTL.

In general, the population count has increased for all the countries in Africa (Fig. 6). Countries with the highest increase are Nigeria, Ethiopia, Egypt, Uganda, Democratic Republic of Congo Tanzania and Kenya. These are just the outstanding ones among all the increases in population count in the continent. It is important to point out that although some countries are more developed than others, the tendency of 
population and NTL, if not disturbed by any natural disasters or armed conflict, is set to increase. However, the increase in population is not directly correlated with NTL increase, as we have seen in some countries in Africa, where the electricity consumption are diverted to other sectors other than residential and NTL are mostly representative of cities, towns and other places with persistent lights that can be detected at night by the satellite.

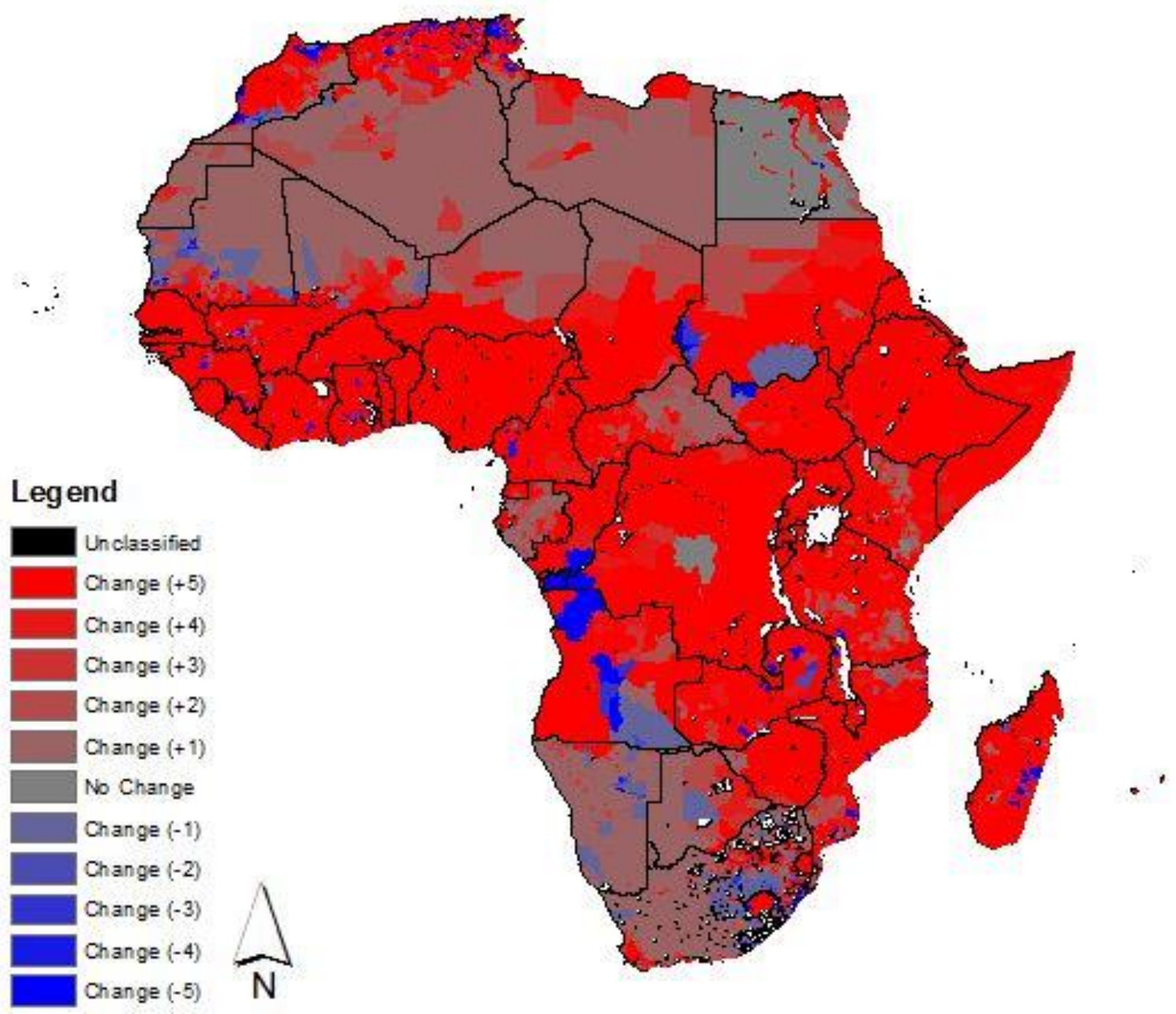

Fig. 6. Changes in population count per $\mathrm{km}^{2}$ between 2000 and 2013.

In general, in most of the sub-Saharan countries, the population count has had a positive change. However, there can be some sources of uncertainty for both population count and NTL data sets. The uncertainties could be a result of the different approaches in collecting the data, and the satellite sensitivity loss during the years.

\subsection{Combined Results of Decomposition Analysis and Satellite Derived Data Assessment}

Average continent-wide NTL has increased by $43 \%$ since 2000 . However, the growth was unequal between the groups. The NTL has increased in high, medium and low NTL countries by $11 \%, 32 \%$ and $18 \%$ respectively since 2000 . Population count in high, medium and low NTL countries by $27 \%, 39 \%$ and $32 \%$ respectively since 2000 .

The countries where NTL has declined since 2000 include Cameroon, Cote d'Ivoire, Ghana, Zimbabwe, Cabo Verde, Comoros, Guinea-Bissau, Lesotho, Madagascar, Malawi, Seychelles and Swaziland. Meanwhile, the highest increase in NTL was observed in Congo. The economic activity decline was observed in Libya, Cote d'Ivoire, Zimbabwe, Central African Republic, Comoros, Liberia, Madagascar and Togo, while GDP in Equatorial Guinea has increased by 194\% since 2000. Electricity intensity of GDP has declined since 2000 
in South Africa, DR Congo, Ghana, Namibia, Zambia, Zimbabwe, Guinea, Malawi, Mali, Sierra Leone, Swaziland, Chad and Uganda, while the highest growth was observed in Mozambique.

Figure 7 presents the graph of NTL and population count in high NTL countries in 2013. It is shown that Nigeria may face the urgent need to improve its electricity supply due to fast total population (41\%) and population count per $\mathrm{km}^{2}(39 \%)$ growth. Egypt may have similar problems if the current population growth and urbanization rate persist. In total, population count growth since 2000 in high NTL countries was the slower $(27 \%)$ comparing with other groups. The combination of the highest NTL in Africa, modest population count, diverse electricity mix and the highest installed capacity of power plants in the continent makes South Africa relatively safe in terms of energy security. The only factor of concern in South Africa is access to electricity ( $85 \%$ of total population and $67 \%$ of rural population).

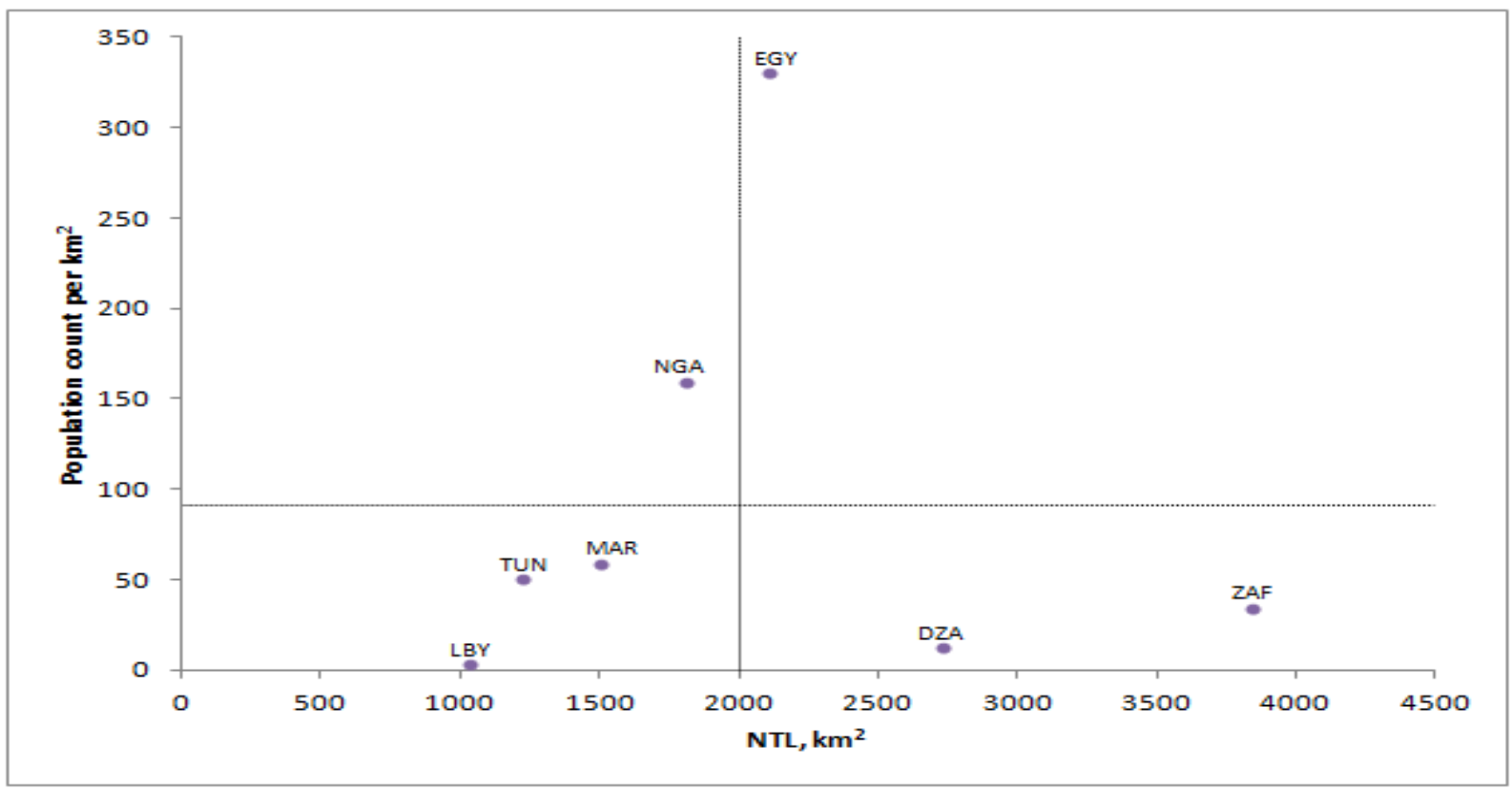

Fig. 7. NTL and population count in high NTL African countries in 2013.

Libya and South Africa have experienced below average electricity consumption and NTL growth for period under investigation as shown in Fig. 8. It is possible that in the case of Egypt and Nigeria electricity consumption growth did not result in subsequent NTL increase due to higher population growth and urbanization. NTL has remained almost unchanged in Libya since 2000. 


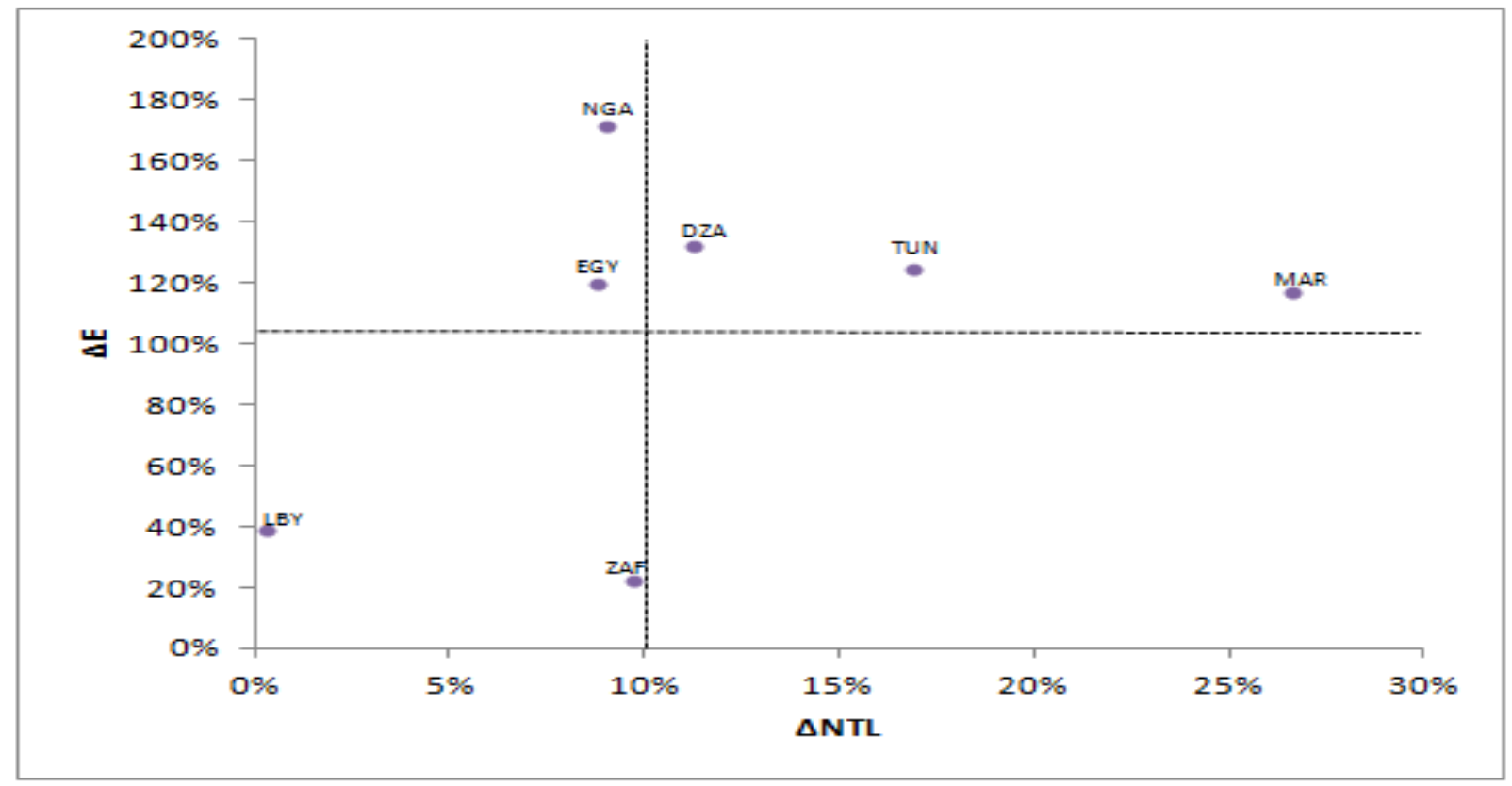

Fig. 8. Changes in NTL and electricity consumption in high NTL African countries, 2000-2013.

The issue of electricity supply could become crucial for medium NTL Cameroon, Ethiopia, Senegal and Tanzania due to higher population count as seen in Fig. 9. Average population count in medium NTL countries has increased by $39 \%$ since 2000, faster than in other groups. However, the lower growth was observed in Botswana, Cote d'Ivoire, Namibia and Zimbabwe by 24\%, 30\%, 23\% and 18\% respectively. Population count in Namibia is the lowest in Africa, followed by Botswana and Libya.

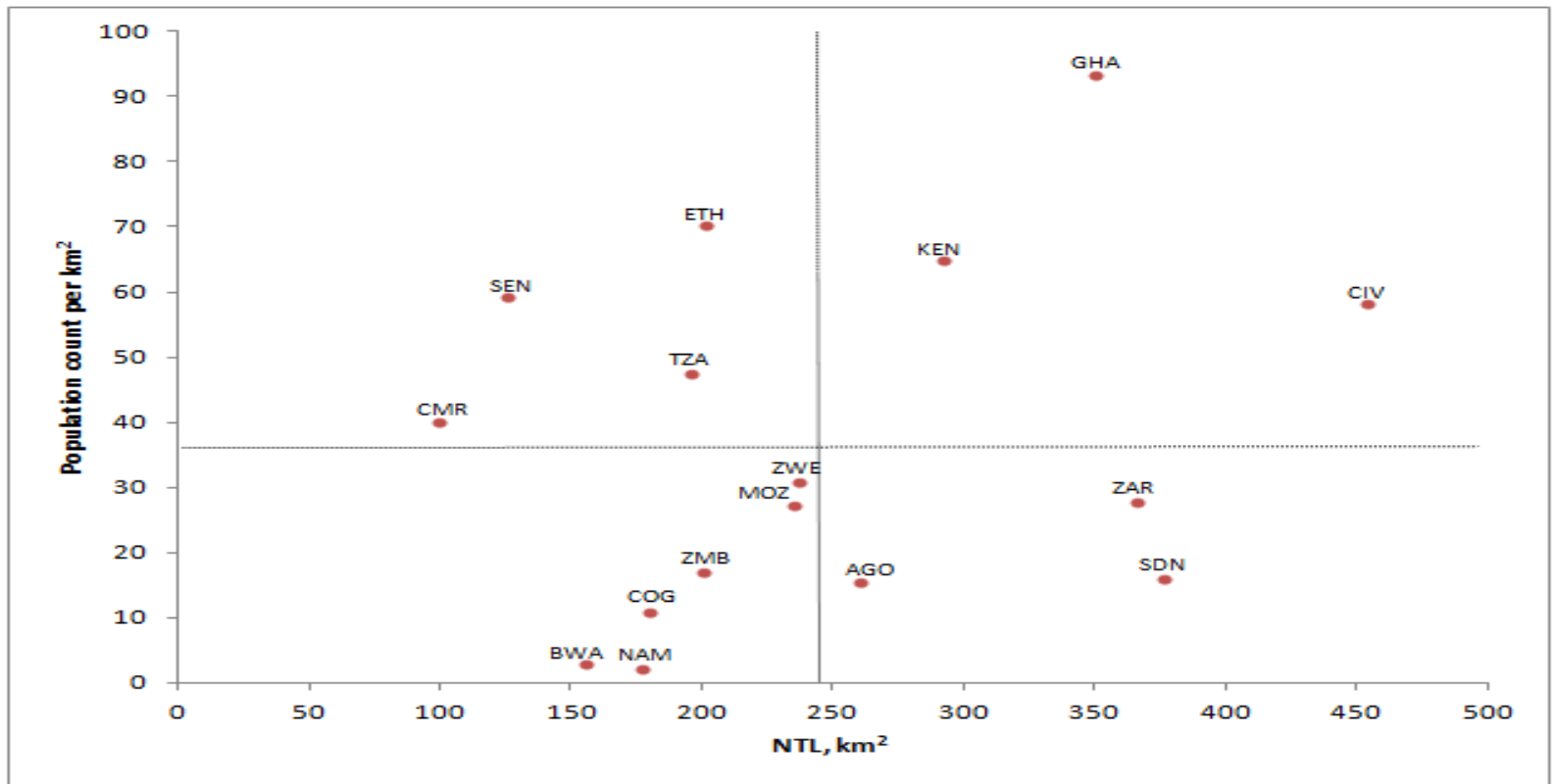

Fig. 9. NTL and population count in medium NTL African countries in 2013.

Angola, Ethiopia, Congo, Mozambique and Sudan (former) have achieved significant increase in electricity consumption since 2000 as displayed in Fig. 10. It was primarily due to stronger economic growth and increased expansion of power plant capacities. NTL in Congo and DR Congo have increased by $431 \%$ and 316\% respectively since 2000. Although Cote d'Ivoire has the largest lit area among the medium NTL countries, the indicator has declined since 2000 due to slower economic growth. It is likely that the ongoing economic and political crisis in Zimbabwe affected both electricity consumption and NTL area. 


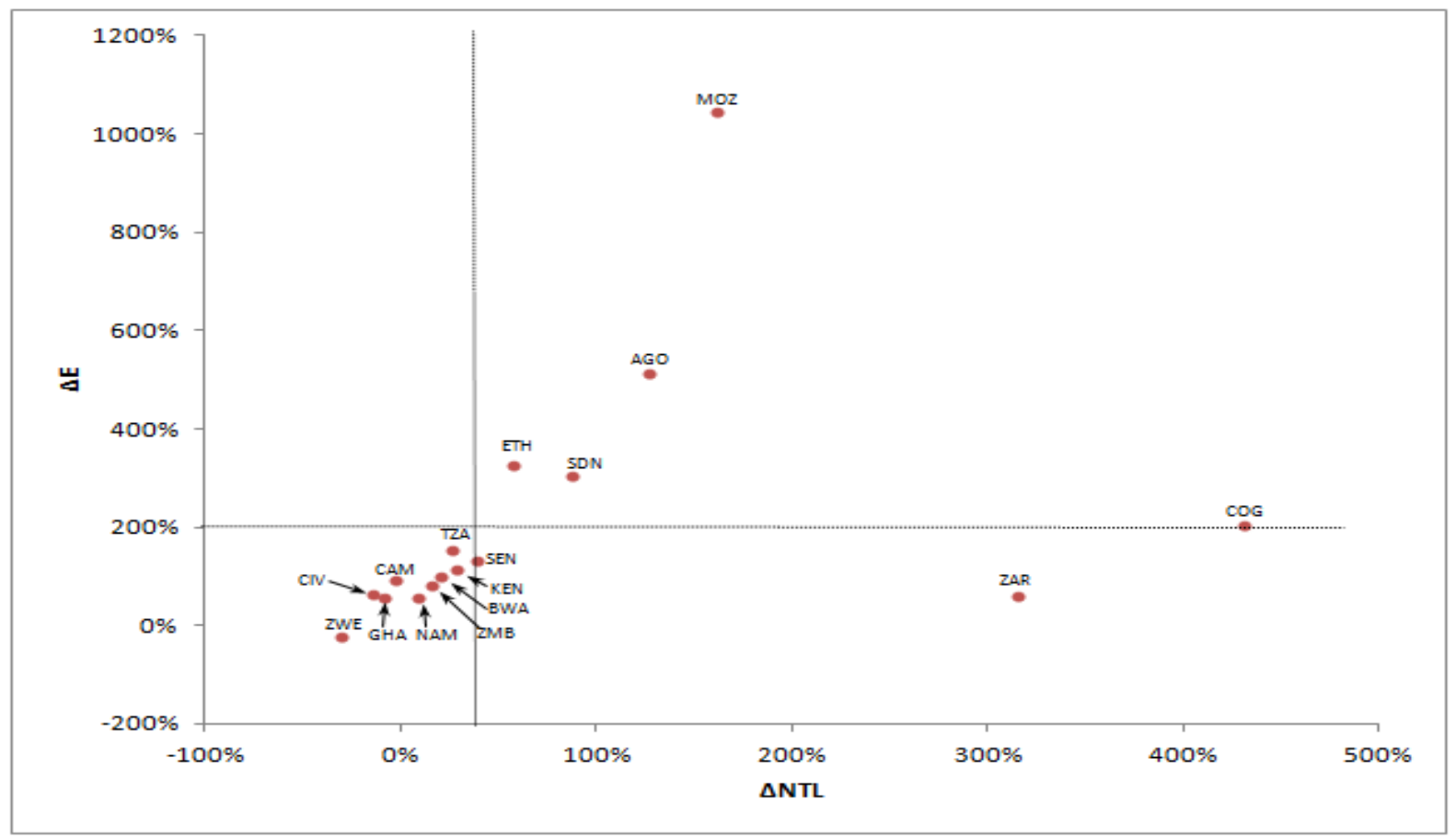

Fig. 10. Changes in NTL and electricity consumption in medium NTL African countries, 2000-2013.

There is a notable contrast in both NTL and population count among the low NTL countries as seen in Fig. 11. Comoros, Burundi, Mauritius and Rwanda have significantly higher population count. However, unlike other countries of the group, $100 \%$ of population in Mauritius has access to electricity, while only about $7 \%$ of population in Burundi has access to electricity. Guinea-Bissau is the country with the lowest NTL in Africa, while the population count in Mauritius is the highest in the continent. The highest total population growth in Africa since 2000 was observed in Niger, while the lowest was in Mali.

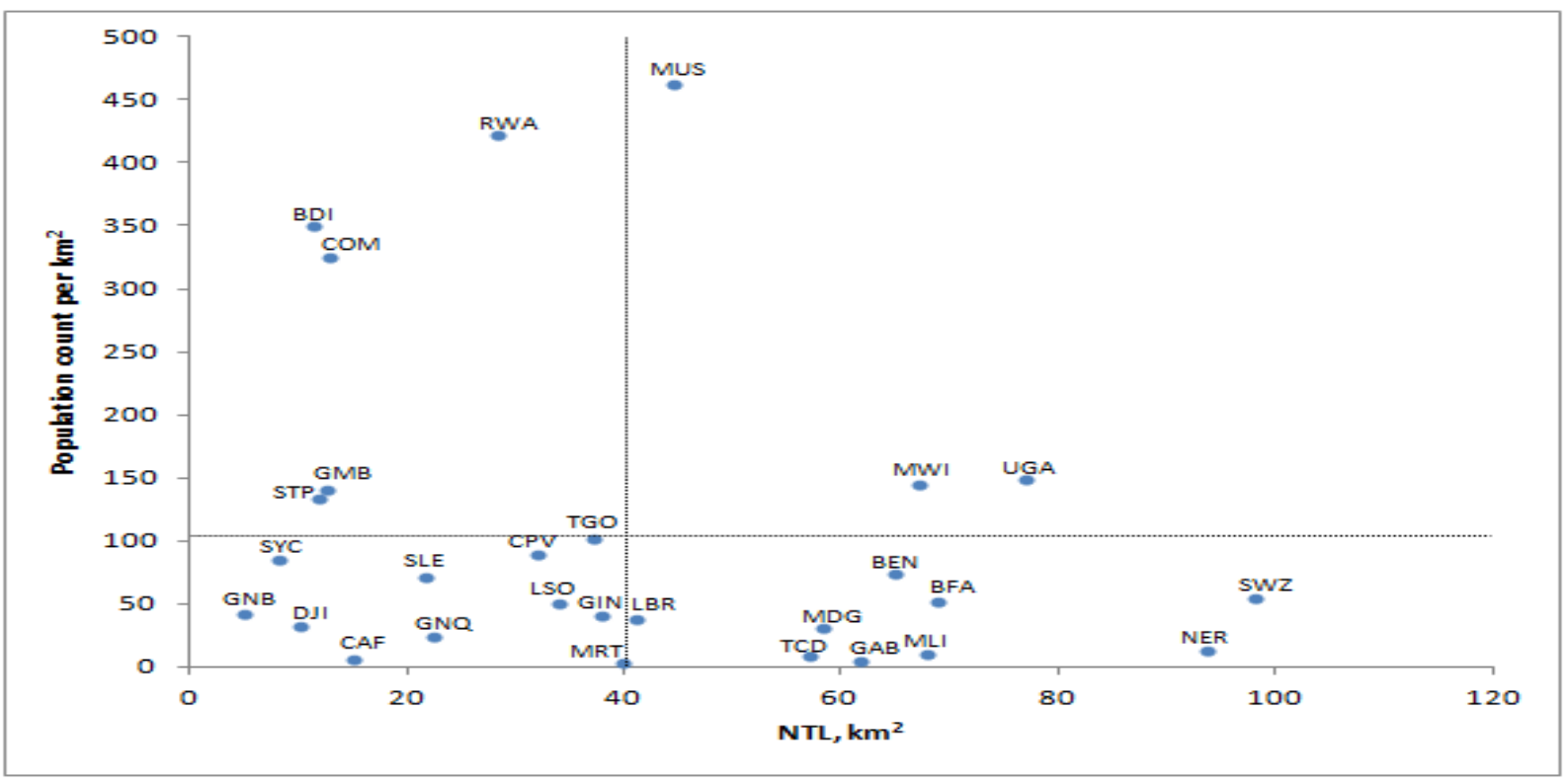

Fig. 11. NTL and population count in low NTL African countries in 2013.

Equatorial Guinea has achieved significant increase in both NTL and electricity consumption since 2000 as shown in Fig. 12. This is due to almost 200\% growth in GDP per capita since 2000. Meanwhile, NTL in Comoros and Guinea-Bissau have dropped notably since 2000 by $77 \%$ and $50 \%$ respectively. 


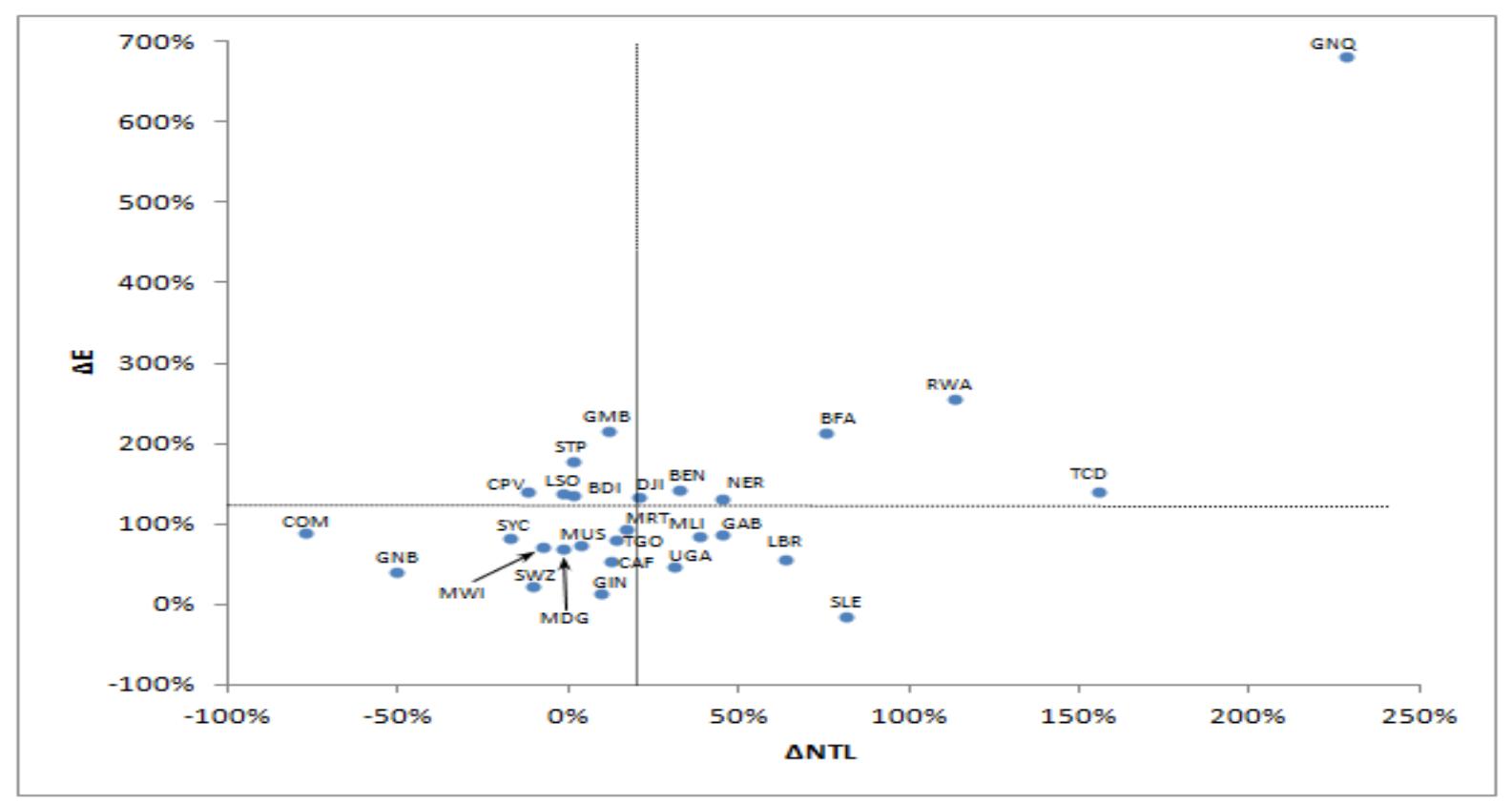

Fig. 12. Changes in NTL and electricity consumption in low NTL African countries, 2000-2013.

\section{Conclusion}

This study is the first attempt to perform continent-level decomposition analysis of electricity consumption, analysis of NTL and population count in order to identify driving factors behind electricity consumption in Africa between 2000 and 2013. The countries were divided into three groups based on the lit area: high, medium and low NTL. Prior to analysis, the energy profiles of the countries were assessed.

It was identified that the energy profiles of African countries vary significantly due to differences in resource availability, infrastructure and stages of economic. This resulted in the significant differences in the rate of electrification between more-developed and less-developed countries of the continent. Furthermore, there is a particularly large gap in the access to electricity between urban and rural population within the countries, primarily medium and low NTL states. The solution of energy poverty issues is going to positively impact economic development of the continent.

The results of decomposition analysis revealed that the economic activity and electricity intensity were the main factors behind increase in electricity consumption in high NTL countries. In medium NTL countries, the increase in electricity consumption was primarily attributed to population and electricity intensity growth. The same applies to low NTL countries. Population growth had a positive impact on electricity consumption in all countries of the continent, while the decline in electricity intensity caused a decrease in electricity use in some medium and low NTL countries.

It is likely that promotion of energy efficiency in high NTL countries in Africa will have positive effect on economic growth. Medium and low NTL countries would need to increase power production capacities in order to induce economic growth and address demand caused by growing population. However, there is an urgent need for better institutions, financing mechanisms, laws and regulation to promote a sustainable energy future in Africa [51].

Analysis of satellite derived NTL and population count data indicated the changes in both indicators between 2000 and 2013. In general, it could be said that urbanization rate has been on rise, causing increase of indicators in urban areas and decline in rural parts. It is likely indicating that electricity infrastructure and economic rural development trails behind in most of the countries of the continent. Combined assessment of decomposition results and satellite derived data contributed to better understanding of the differences between the countries of different groups.

The results of this study could be used not only to design better energy policies, but also could contribute to improve urban planning, resource management and economic policy development in Africa. Further studies will include the use of a multi-regional spatial decomposition model for electricity consumption [24], 
and country-level benchmarking for improved NTL assessment based on the country or regional thresholding procedure as well as a shorter time span as a straight ten years period can hide fluctuations in satellite derived data along the years. Furthermore, there is a need for map overlay analysis of NTL map with solar and wind potential maps as it is likely that development of renewable energy, particularly community-based off-grid systems, could be a solution for Africa's energy poverty. On top of that, map overlay analysis of NTL and population data with gas flares could contribute to assessment of market and potential of utilization of flared gas for the generation of electricity on the continent.

\section{References}

[1] I. M. Bugaje, "Renewable energy for sustainable development in Africa," Renewable and Sustainable Energy Reviews, vol. 10, no. 6, pp. 603-612, December 2006.

[2] International Energy Agency, "Africa Energy Outlook. World Energy Outlook special report," OECD/IEA, Paris, France, 2014.

[3] E. Kebede, J. Kagochi, and C. M. Jolly, "Energy consumption and economic development in SubSaharan Africa," Energy Economics, vol. 32, pp. 532-537, 2010.

[4] E. Panos, H. Turton, M. Densing, and K. Volkart, "Powering the growth of Sub-Saharan Africa: The jazz and symphony scenarios of World Energy Council," Energy for Sustainable Development, vol. 26, pp.1433, June 2015.

[5] A. Brew-Hammond, "Energy access in Africa: Challenges ahead," Energy Policy, vol. 38, no. 5, pp. 22912301, May 2010.

[6] I. Onyeji, M. Bazilian, and P. Nussbaumer, "Contextualizing electricity access in Sub-Saharan Africa," Energy for Sustainable Development, vol. 16, no. 4, pp. 520-527, December 2012.

[7] S. Kazrekezi, "Poverty and energy in Africa - A brief review," Energy Policy, vol. 30, no. 11-12, pp. 915919, September 2002.

[8] V. Foster and C. Briceno-Garmendia, "Africa's infrastructure: A time for transformation," The International Bank/The World Bank, Washington, DC, USA, 2010.

[9] A. Eberhard, V. Foster, C. Briceno-Garmendia, F. Ouedraogo, D. Camos, and M. Shkaratan, "Underpowered: The state of the power sector in Sub-Saharan Africa," Africa Infrastructure Sector Diagnostic, World Bank, Washington DC, USA, Background Paper 6, 2008.

[10] N. S. Ouedraogo, "Modeling sustainable long-term electricity," Applied Energy, vol. 190, pp. 1046-1067, March 2017.

[11] African Development Bank, "Energy sector policy of the AfDB Group," Operational Resources and Policies Department (ORPC), 2012.

[12] Economic Community of West African States, "The ECOWAS Energy Efficiency Policy (EEEP)," ECOWAS Regional Centre for Renewable Energy and Efficiency (ECREEE), Praia, Cape Verde, 2012.

[13] Economic Community of West African States, "ECOWAS Renewable Energy Policy (EREP)," ECOWAS Regional Centre for Renewable Energy and Efficiency (ECREEE), Praia, Cape Verde, 2015.

[14] The United States Agency for International Development. (2017). Power Africa [Online]. Available: https://www.usaid.gov/powerafrica [Accessed: 25 March 2017]

[15] Akon Lighting Africa. (2017). Our Activities [Online]. Available: http://akonlightingafrica.com/ouractivities/overview/ [Accessed: 25 March 2017]

[16] The World Economic Forum. (2017). Energy Access Africa [Online]. Available: https://www.weforum.org/projects/energy-access-africa [Accessed: 25 March 2017]

[17] The Africa Renewable Energy Initiative. About AREI [Online]. Available: http://www.arei.org/ [Accessed: 25 March 2017]

[18] M. Bazilian, P. Nussbaumer, H. H. Rogner, A. Brew-Hammond, V. Foster, S. Pachauri, E. Williams, M. Howells, P. Niyongabo, L. Musaba, B. O. Gallachoir, M. Radka, and D. M. Kammen, "Energy access scenarios to 2030 for the power sector in sub-Saharan Africa," Utilities Policy, vol. 20, no. 1, pp. 1-16, 2012.

[19] A. Brew-Hammond and F. Kemausour, "Energy for all in Africa - to be or not to be?," Current Opinion in Environmental Sustainability, vol. 1, no. 1, pp. 83-88, October 2009.

[20] A. Ben Hammamia, A. Dakhlaoui, and A. Abassia, "Analysis of the decomposition of energy intensity in Tunisia," International Journal of Energy Economics and Policy, vol. 4, no. 3, pp. 420-426, 2014.

[21] R. Ingesi-Lotz and J. N. Blignaut, "South Africa's electricity consumption: A sectoral decomposition analysis," Applied Energy, vol. 88, no.12, pp. 4779-4784, December 2011. 
[22] O. A. Olanrewaju, A. A. Jimoh, and P. A. Kholopane, "Assessing the energy potential in the South African industry: A combined IDA-ANN-DEA (Index Decomposition Analysis-Artificial Neural Network-Data Envelopment Analysis) model," Energy, vol. 63, pp. 225-232, December 2013.

[23] The US Energy Information Administration, "Drivers of U.S. household energy consumption, 19802009," U.S. Department of Energy, Washington, DC, February 2015.

[24] B. W. Ang, X. Y. Xu, and S. Bin, "Multi-country comparisons of energy performance: the index decomposition analysis approach," Energy Economics, vol. 47, pp. 68-76, 2015.

[25] S. Mukherjee, "Decomposition analysis of electricity consumption: A state-wise assessment," Economic and Political Weekly, vol. 43, no. 3, pp. 57-64, January 2008

[26] Y. Tanoto and M. Praptiningsih, "Factors decomposition of Indonesia's household electricity consumption," Engineering Journal, vol. 17, no. 2, pp. 19-28, 2013.

[27] C. D. Elvidge, P. C. Sutton, T. Ghosh, B. T. Tuttle, K. E. Baugh, B. Bhaduri, and E. Bright, "A global poverty map derived from satellite data," Computer \& Geosciences, vol. 35, no. 8, pp. 1652-1660, August 2009.

[28] C. Small, F. Pozzi, and C.D. Elvidge, "Spatial analysis of global urban extent from DMSP-OLS night lights," Remote Sensing of Environment, vol. 96, pp. 277-291, 2005.

[29] T.A. Croft, "Burning waste gas in oil fields," Nature, vol. 245, pp. 375-376, 1973.

[30] T. Ma, Y. Zhou, C. Zhou, S. Haynie, T. Pei, and T. Xu, "Night-time light derived estimation of spatiotemporal characteristics of urbanization dynamics DMSP/OLS satellite data," Remote Sensing of Environment, vol. 158, pp. 453-464, 2015.

[31] M. L. Imhof, W. T. Lawrence, D. C. Stutzer, and C. D. Elvidge, "A technique for using composite DMSP/OLS "City Lights" satellite data to map urban area," Remote Sensing of Environment, vol. 61, no. 3, pp. 361-370, September 1997.

[32] C. N. H. Doll and S. Pachauri, "Estimating rural populations without access to electricity in developing countries through night-time light satellite imagery," Energy Policy, vol. 38, no. 10, pp. 5661-5670, October, 2010.

[33] B. Min, K. M. Gaba, O. F. Sarr, and A. Agalassou, "Detecting of rural electrification in Africa using DMSP-OLS night lights imagery," International Journal of Remote Sensing, vol. 34, no. 22, pp. 8118-8141, 2013.

[34] Y. Wolde-Rufael, "Energy consumption and economic growth: The experience of African countries revisited," Energy Economics, vol. 31, pp. 217-224, 2009.

[35] N. Khraief, O. E. Omoju, and M. Shahbaz, "Are fluctuations in electricity consumption per capita in Sub-Saharan Africa countries transitory or permanent?," Energy Strategy Reviews, vol. 13-14, pp. 86-96, 2016.

[36] United Nations Statistics Division. (2017). UNdata [Online]. Available: http://data.un.org [Accessed: 25 March 2017]

[37] G. Prasad, "Energy sector reform, energy transitions and the poor in Africa," Energy Policy, vol. 36, pp. 2806-2811, 2008.

[38] The World Bank Group. (2017). World Bank Open Data [Online]. Available: http://data.worldbank.org/ [Accessed: 25 March 2017]

[39] B. W. Ang and F. Q. Zhang, "A survey of index decomposition analysis in energy and environmental studies," Energy, vol. 25, pp. 1149-1176, 2000.

[40] B. W. Ang, "Decomposition analysis for policymaking in energy: which is preferred method?," Energy Policy, vol. 32, pp. 1131-1139, 2004.

[41] United Nations, "International recommendations for energy statistics (IRES)," United Nations Publication, New York, USA, 2016.

[42] United Nations, "Energy statistics: Definitions, units of measure and conversion factors," Department of International Economic and Social Affairs, United Nations Publication, New York, USA, 1987.

[43] United Nations, "Energy statistics: A manual for developing countries," Department of International Economic and Social Affairs, United Nations Publication, New York, USA, 1991.

[44] Center for International Earth Science Information Network, "Documentation for the Gridded Population of the World. Version 4 (GWP v4)," NASA, Columbia University, Palisades, NY, USA, 2016.

[45] National Oceanic and Atmospheric Administration. (2017). National Geophysical Data Center [Online]. Available: https://ngdc.noaa.gov/eog/dmsp/downloadV4composites.html [Accessed: 25 March 2017] 
[46] National Oceanic and Atmospheric Administration. (2017). Global Gas Flaring Shapefiles [Online]. Available: https://ngdc.noaa.gov/eog/interest/gas_flares_countries_shapefiles.html [Accessed: 25 March 2017]

[47] C. D. Elvidge, D. Ziskin, K. E. Baugh, B. T. Tuttle, T. Ghosh, D. E. Pack, E. H. Erwin, and M. Zhizhin, "A fifteen year record of global natural gas flaring derived from satellite data," Energies, vol. 2, no. 3, pp. 565-622, 2009.

[48] The National Aeronautics and Space Administration. (2017). Socioeconomic Data and Applications Center (SEDAC) [Online]. Available: http://sedac.ciesin.columbia.edu/data/set/gpw-v4-population-countadjusted-to-2015-unwpp-countrytotals/data-download\# [Accessed: 25 March 2017]

[49] C. N. H. Doll, "CIESIN thematic guide to night-time light remote sensing and its applications," NASA, Columbia University, Palisades, NY, USA, 2008.

[50] F. Q. Zhang and B. W. Ang, "Methodological issues in cross-country/region decomposition of energy and environment indicators," Energy Economics, vol. 23, no. 2, pp. 179-190, March 2001.

[51] United Nations Development Programme, "World energy assessment: Overview 2004 update," Bureau for Development Policy, New York, USA, 2004. 
Appendix I. Socioeconomic and Electricity Indicators in Africa, 2013

\begin{tabular}{|c|c|c|c|c|c|c|c|c|}
\hline \multirow[t]{3}{*}{ Country } & \multirow{3}{*}{$\begin{array}{c}\text { GDP } \\
\text { PPP(2011) } \\
\text { \$/capita }\end{array}$} & \multirow{2}{*}{$\begin{array}{c}\text { Electricity } \\
\text { intensity } \\
\text { MWh/PPP } \\
\text { (2011)M\$ }\end{array}$} & \multirow{2}{*}{$\begin{array}{c}\text { Installed } \\
\text { capacity } \\
\text { MW }\end{array}$} & \multirow{2}{*}{$\begin{array}{c}\text { Total } \\
\text { population } \\
\text { Million }\end{array}$} & \multirow{3}{*}{$\begin{array}{l}\text { Urban } \\
\% \text { of } \\
\text { total }\end{array}$} & \multicolumn{3}{|c|}{$\begin{array}{l}\text { FY } 2012 \text { access to } \\
\text { electricity, } \%\end{array}$} \\
\hline & & & & & & Total & Urban & Rural \\
\hline & & \multicolumn{6}{|c|}{ High NTL (NTL>1000 km²) } & \\
\hline Algeria & 13314 & $85^{\circ}$ & 15097 & 38.2 & 70 & 100 & 100 & 100 \\
\hline Egypt & 10050 & 156 & 32702 & 87.6 & 43 & 100 & 100 & 100 \\
\hline Libya & 19557 & 115 & 9455 & 6.3 & 78 & 100 & 100 & 100 \\
\hline Morocco & 7192 & 116 & 7013 & 33.5 & 59 & 100 & 100 & 100 \\
\hline Nigeria & 5448 & 25 & 9822 & 172.8 & 46 & 56 & 84 & 34 \\
\hline South Africa & 12446 & 301 & 44170 & 53.2 & 64 & 85 & 97 & 67 \\
\hline Tunisia & 10613 & 127 & 4539 & 10.9 & 66 & 100 & 100 & 100 \\
\hline \multicolumn{9}{|c|}{ Medium NTL $\left(1000 \mathrm{~km}^{2}>\right.$ NTL $\left.>100 \mathrm{~km}^{2}\right)$} \\
\hline Angola & 6858 & 44 & 1530 & 23.4 & 42 & 37 & 83 & 6 \\
\hline Botswana & 15022 & 101 & 753 & 2.2 & 57 & 53 & 71 & 24 \\
\hline Cameroon & 2745 & 86 & 1571 & 22.2 & 53 & 54 & 88 & 19 \\
\hline Congo & 5749 & 32 & 390 & 4.4 & 65 & 42 & 59 & 12 \\
\hline Cote d'Ivoire & 2934 & 75 & 1525 & 21.6 & 53 & 56 & 88 & 29 \\
\hline DR Congo & 673 & 148 & 2606 & 72.6 & 41 & 16 & 36 & 6 \\
\hline Ethiopia & 1330 & 48 & 2311 & 94.6 & 19 & 27 & 100 & 8 \\
\hline Ghana & 3834 & 94 & 3041 & 26.2 & 53 & 64 & 85 & 41 \\
\hline Kenya & 2748 & 61 & 1723 & 43.7 & 25 & 23 & 58 & 7 \\
\hline Mozambique & 1033 & 424 & 2646 & 26.5 & 32 & 20 & 55 & 5 \\
\hline Namibia & 9140 & 176 & 487 & 2.3 & 45 & 47 & 94 & 17 \\
\hline Senegal & 2191 & 99 & 854 & 14.2 & 43 & 57 & 88 & 27 \\
\hline Sudan & 3409 & 49 & 3199 & 50.0 & 30 & 26 & 55 & 14 \\
\hline Tanzania & 2268 & 42 & 1115 & 50.2 & 30 & 15 & 46 & 4 \\
\hline Zambia & 3556 & 200 & 2038 & 15.2 & 40 & 22 & 47 & 6 \\
\hline Zimbabwe & 1684 & 330 & 2112 & 14.9 & 33 & 40 & 78 & 16 \\
\hline \multicolumn{9}{|c|}{ Low NTL (NTL<100 km²) } \\
\hline Benin & 1867 & 50 & 208 & 10.3 & 43 & 38 & 68 & 15 \\
\hline Burkina Faso & 1530 & 40 & 298 & 17.1 & 28 & 13 & 49 & 1 \\
\hline Burundi & 725 & 34 & 39 & 10.5 & 11 & 7 & 59 & 1 \\
\hline Cabo Verde & 6130 & 94 & 142 & 0.5 & 64 & 71 & 84 & 47 \\
\hline Central African & 561 & 61 & 44 & 4.7 & 40 & 11 & 15 & 8 \\
\hline \multicolumn{9}{|l|}{ Rep. } \\
\hline Chad & 2005 & 8 & 47 & 13.1 & 22 & 6 & 18 & 3 \\
\hline Comoros & 1369 & 42 & 24 & 0.8 & 28 & 69 & 85 & 61 \\
\hline Djibouti & 2983 & 119 & 130 & 0.9 & 77 & 53 & 65 & 13 \\
\hline Equatorial & 34233 & 13 & 334 & 0.8 & 40 & 66 & 93 & 43 \\
\hline \multicolumn{9}{|l|}{ Guinea } \\
\hline Gabon & 18172 & 61 & 514 & 1.7 & 87 & 89 & 98 & 45 \\
\hline Gambia & 1593 & 70 & 91 & 1.9 & 58 & 35 & 41 & 26 \\
\hline Guinea & 1192 & 51 & 518 & 11.9 & 36 & 26 & 74 & 3 \\
\hline Guinea-Bissau & 1336 & 15 & 27 & 1.8 & 48 & 61 & 100 & 21 \\
\hline Lesotho & 2459 & 139 & 80 & 2.1 & 26 & 21 & 47 & 10 \\
\hline Liberia & 817 & 73 & 91 & 4.3 & 49 & 10 & 19 & 1 \\
\hline Madagascar & 1367 & 39 & 508 & 22.9 & 34 & 15 & 61 & 8 \\
\hline Malawi & 1088 & 101 & 502 & 16.2 & 16 & 10 & 37 & 2 \\
\hline Mali & 2090 & 37 & 811 & 16.6 & 38 & 26 & 50 & 12 \\
\hline Mauritania & 3633 & 50 & 263 & 3.9 & 59 & 22 & 46 & 4 \\
\hline Mauritius & 17148 & 110 & 778 & 1.3 & 40 & 100 & 100 & 100 \\
\hline Niger & 877 & 52 & 176 & 18.4 & 18 & 14 & 62 & 5 \\
\hline
\end{tabular}


Appendix I. Socioeconomic and Electricity Indicators in Africa, 2013 (Contd.)

\begin{tabular}{|c|c|c|c|c|c|c|c|c|}
\hline \multirow[t]{2}{*}{ Country } & \multirow{2}{*}{$\begin{array}{c}\text { GDP } \\
\text { PPP(2011) } \\
\text { \$/capita }\end{array}$} & \multirow{2}{*}{$\begin{array}{c}\text { Electricity } \\
\text { intensity } \\
\text { MWh/PPP } \\
(2011) \mathrm{M} \$\end{array}$} & \multirow{2}{*}{$\begin{array}{c}\text { Installed } \\
\text { capacity } \\
\text { MW }\end{array}$} & \multirow{2}{*}{$\begin{array}{c}\text { Total } \\
\text { population } \\
\text { Million }\end{array}$} & \multirow{2}{*}{$\begin{array}{l}\text { Urban } \\
\% \text { of } \\
\text { total }\end{array}$} & \multicolumn{3}{|c|}{$\begin{array}{c}\text { FY } 2012 \text { access to } \\
\text { electricity, } \%\end{array}$} \\
\hline & & & & & & Total & Urban & Rural \\
\hline Rwanda & 1516 & 23 & 109 & 11.1 & 27 & 18 & 62 & 8 \\
\hline $\begin{array}{l}\text { Sao Tome \& } \\
\text { Principe }\end{array}$ & 2963 & 94 & 19 & 0.2 & 64 & 60 & 68 & 47 \\
\hline Seychelles & 24805 & 138 & 85 & 0.1 & 53 & 61 & 100 & 17 \\
\hline Sierra Leone & 1876 & 6 & 77 & 6.2 & 39 & 14 & 47 & 1 \\
\hline Swaziland & 7836 & 125 & 164 & 1.3 & 21 & 42 & 100 & 24 \\
\hline Togo & 1296 & 104 & 227 & 6.9 & 39 & 31 & 68 & 9 \\
\hline Uganda & 1665 & 34 & 838 & 36.6 & 15 & 18 & 71 & 8 \\
\hline
\end{tabular}

Source: Authors' calculations using World Bank and UN Data [19, 21].

Appendix II. The results of decomposition analysis, 2000-2013

\begin{tabular}{|c|c|c|c|c|c|c|c|c|c|}
\hline \multirow{2}{*}{\multicolumn{10}{|c|}{$\frac{\text { GWh }}{\mathrm{L}}$}} \\
\hline & & & & & & & & & \\
\hline Algeria & DZA & 24566 & 10917 & 7739 & 5909 & 132 & 59 & 42 & 32 \\
\hline Egypt & EGY & 74995 & 24179 & 27151 & 23664 & 120 & 39 & 43 & 38 \\
\hline Libya & LBY & 3934 & 3420 & -1410 & 1924 & 39 & 34 & -14 & 19 \\
\hline Morocco & MAR & 15008 & 3189 & 9017 & 2802 & 117 & 25 & 70 & 22 \\
\hline Nigeria & NGA & 14844 & 87 & 9693 & 5064 & 172 & 1 & 112 & 59 \\
\hline South Africa & $\mathrm{ZAF}$ & 36792 & -38186 & 40774 & 34204 & 23 & -23 & 25 & 21 \\
\hline Tunisia & TUN & 8177 & 3654 & 3204 & 1320 & 125 & 56 & 49 & 20 \\
\hline \multicolumn{10}{|c|}{ Medium NTL $\left(1000 \mathrm{~km}^{2}>\right.$ NTL $\left.>100 \mathrm{~km}^{2}\right)$} \\
\hline Angola & AGO & 5930 & 2576 & 1905 & 1449 & 513 & 223 & 165 & 125 \\
\hline Botswana & BWA & 1640 & 207 & 891 & 541 & 98 & 12 & 53 & 32 \\
\hline Cameroon & CMR & 2550 & 757 & 511 & 1282 & 94 & 28 & 19 & 47 \\
\hline Congo & COG & 537 & 266 & 103 & 168 & 203 & 100 & 39 & 63 \\
\hline Cote d'Ivoire & CIV & 1847 & 887 & -55 & 1015 & 63 & 30 & -2 & 35 \\
\hline DR Congo & ZAR & 2719 & -1178 & 1513 & 2385 & 60 & -26 & 33 & 53 \\
\hline Ethiopia & ETH & 4659 & 1067 & 2458 & 1134 & 326 & 75 & 172 & 79 \\
\hline Ghana & GHA & 3409 & -3102 & 3995 & 2516 & 56 & -51 & 66 & 41 \\
\hline Kenya & $\mathrm{KEN}$ & 3888 & 913 & 1233 & 1742 & 114 & 27 & 36 & 51 \\
\hline Mozambique & MOZ & 10592 & 6285 & 2695 & 1611 & 1046 & 620 & 266 & 159 \\
\hline Namibia & NAM & 1386 & -475 & 1219 & 642 & 58 & -20 & 51 & 27 \\
\hline Senegal & SEN & 1742 & 706 & 272 & 765 & 130 & 53 & 20 & 57 \\
\hline Sudan & $\mathrm{SDN}$ & 6252 & 2731 & 1896 & 1624 & 304 & 133 & 92 & 79 \\
\hline Tanzania & TZA & 2923 & 278 & 1416 & 1230 & 153 & 15 & 74 & 64 \\
\hline Zambia & ZMB & 4817 & -2532 & 4356 & 2993 & 80 & -42 & 72 & 50 \\
\hline Zimbabwe & ZWE & -2209 & -78 & -3771 & 1640 & -21 & -1 & -36 & 16 \\
\hline \multicolumn{10}{|c|}{ Low NTL (NTL<100 km²) } \\
\hline Benin & $\mathrm{BEN}$ & 569 & 234 & 81 & 254 & 143 & 59 & 20 & 64 \\
\hline Burkina Faso & $\mathrm{BFA}$ & 707 & 233 & 235 & 239 & 214 & 70 & 71 & 72 \\
\hline Burundi & BDI & 149 & 70 & 3 & 76 & 136 & 64 & 3 & 69 \\
\hline Cabo Verde & $\mathrm{CPV}$ & 170 & 49 & 93 & 28 & 140 & 40 & 76 & 23 \\
\hline Central African Republic & $\mathrm{CAF}$ & 57 & 78 & -52 & 31 & 55 & 75 & -50 & 29 \\
\hline Chad & TCD & 120 & -39 & 97 & 62 & 140 & -45 & 112 & 73 \\
\hline Comoros & $\mathrm{COM}$ & 21 & 12 & -1 & 10 & 90 & 50 & -5 & 44 \\
\hline Djibouti & DJI & 175 & 67 & 71 & 37 & 134 & 51 & 54 & 28 \\
\hline Equatorial Guinea & GNQ & 314 & 88 & 164 & 62 & 683 & 190 & 357 & 135 \\
\hline
\end{tabular}


Appendix II. The results of decomposition analysis, 2000-2013 (Contd.)

\begin{tabular}{lccccccccc}
\hline Country & Code & $\boldsymbol{\Delta} \boldsymbol{E}$ & $\boldsymbol{\Delta} \boldsymbol{E}_{\text {int }}$ & $\boldsymbol{\Delta} \boldsymbol{E}_{\text {act }}$ & $\boldsymbol{\Delta} \boldsymbol{E}_{\boldsymbol{p o p}}$ & $\boldsymbol{\Delta} \boldsymbol{E}$ & $\boldsymbol{\Delta} \boldsymbol{E}_{\text {int }}$ & $\boldsymbol{\Delta} \boldsymbol{E}_{\text {act }}$ & $\boldsymbol{\Delta} \boldsymbol{E}_{\boldsymbol{p o p}}$ \\
Gabon & GAB & 855 & 424 & 30 & 401 & 87 & 43 & 3 & 41 \\
Gambia & GMB & 143 & 89 & 2 & 52 & 216 & 134 & 3 & 79 \\
Guinea & GIN & 86 & -158 & 35 & 209 & 13 & -25 & 6 & 33 \\
Guinea-Bissau & GNB & 10 & 0 & 1 & 9 & 41 & 2 & 5 & 35 \\
Lesotho & LSO & 414 & 164 & 195 & 55 & 139 & 55 & 66 & 18 \\
Liberia & LIB & 91 & 14 & -5 & 82 & 55 & 8 & -3 & 50 \\
Madagascar & MDG & 503 & 200 & -54 & 356 & 70 & 28 & -7 & 50 \\
Malawi & MWI & 738 & -62 & 292 & 508 & 71 & -6 & 28 & 49 \\
Mali & MLI & 588 & -486 & 684 & 389 & 85 & -70 & 99 & 56 \\
Mauritania & MRT & 344 & 16 & 144 & 184 & 95 & 5 & 40 & 51 \\
Mauritius & MUS & 1010 & 146 & 757 & 108 & 74 & 11 & 55 & 8 \\
Niger & NER & 475 & 117 & 80 & 278 & 131 & 32 & 22 & 77 \\
Rwanda & RWA & 279 & 67 & 141 & 71 & 256 & 62 & 129 & 65 \\
Sao Tome \& Principle & STP & 33 & 12 & 11 & 9 & 179 & 67 & 62 & 50 \\
Seychelles & SYC & 139 & 48 & 68 & 24 & 83 & 28 & 41 & 14 \\
Sierra Leone & SLE & -12 & -88 & 45 & 31 & -15 & -109 & 56 & 39 \\
Swaziland & SWZ & 226 & -102 & 149 & 180 & 23 & -10 & 15 & 18 \\
Togo & TGO & 416 & 170 & -3 & 249 & 80 & 33 & -1 & 48 \\
Uganda & UGA & 657 & -855 & 770 & 742 & 47 & -61 & 55 & 53 \\
\hline
\end{tabular}

